\title{
Experimental and Numerical Evaluation of Progressive Collapse Behavior in Scaled RC Beam-Column Subassemblage
}

\author{
Rasool Ahmadi, ${ }^{1}$ Omid Rashidian, ${ }^{2}$ Reza Abbasnia, ${ }^{2}$ Foad Mohajeri Nav, ${ }^{2}$ and Nima Usefi ${ }^{2}$ \\ ${ }^{1}$ Building and House Research Centre, Tehran, Iran \\ ${ }^{2}$ Civil Engineering Department, Iran University of Science and Technology, Tehran 1684613114, Iran \\ Correspondence should be addressed to Omid Rashidian; omidrashidian@iust.ac.ir
}

Received 28 October 2015; Revised 22 January 2016; Accepted 27 January 2016

Academic Editor: Vadim V. Silberschmidt

Copyright (C) 2016 Rasool Ahmadi et al. This is an open access article distributed under the Creative Commons Attribution License, which permits unrestricted use, distribution, and reproduction in any medium, provided the original work is properly cited.

\begin{abstract}
An experimental test was carried out on a 3/10 scale subassemblage in order to investigate the progressive collapse behavior of reinforced concrete (RC) structures. Investigation of alternative load paths and resistance mechanisms in scaled subassemblage and differences between the results of full-scale and scaled specimens are the main goals of this research. Main characteristics of specimen response including load-displacement curve, mechanism of formation and development of cracks, and failure mode of the scaled specimen had good agreement with the full-scale specimen. In order to provide a reliable numerical model for progressive collapse analysis of RC beam-column subassemblages, a macromodel was also developed. First, numerical model was validated with experimental tests in the literature. Then, experimental results in this study were compared with validated numerical results. It is shown that the proposed macromodel can provide a precise estimation of collapse behavior of RC subassemblages under the middle column removal scenario. In addition, for further evaluation, using the validated numerical model, parametric study of new subassemblages with different details, geometric and boundary conditions, was also done.
\end{abstract}

\section{Introduction}

Evaluating the ability of structures to resist progressive collapse has been the focus of researchers and government agencies for years. Design codes use direct and indirect design methods for protection against progressive collapse. The indirect design method prevents progressive collapse by providing a minimum level of strength, continuity, and ductility of the structure. The direct design method explicitly considers resistance to progressive collapse during the design process. ASCE7-05 [1] has proposed specific local resistance (SLR) and alternative load path (ALP) methods for direct designs.

SLR requires that the building, or parts of the building, provide sufficient strength to resist load. In this method, the strength and ductility of critical elements can be determined during the design process (DOD, 2010) [2]. ALP allows local failure of structural members; however, it prevents extensive structural failure by providing an alternative load path. When a structural member fails, the energy stored in the damaged structural members is released and causes additional loading on the other structural members, which changes the load transmission paths. If the adjacent structural member has enough capacity and ductility to bear the additional loads, the structural system forms an ALP to transfer the load. This method analyzes the building under the effect of one or more structural elements removal. The major advantage of this method is that it is independent of the cause of failure and analysis can be applied to any threat for collapse of an element.

Previous studies by Bao et al. [3], Lew et al. [4, 5], Yi et al. [6], Yu and Tan [7-10], and Su et al. [11] demonstrated that, except for flexural action, reinforced concrete (RC) frames are also able to develop alternative load mechanisms through compressive arch action (CAA) and catenary action (CA). Orton and Kirby [12] and kai and Li [13] discussed dynamic behavior of RC frames under column removal scenarios. Magnusson et al. [14] investigated arching action and enhancement of the shear capacity of RC beams under dynamic out-of-plane loadings. In a recent experimental study, Wang et al. [15] discussed arch and catenary actions on a two-story scaled subassemblage. 
In conventional methods of design, only the flexural mechanism is considered as an ALP, and CAA and CA are beyond the scope of the design codes. CAA is a mechanism of resistance to vertical loads through the development of axial compressive force in beams. Development of this axial force requires the restriction of longitudinal deflection of beams by other members of the frame. CA is resistant to vertical loads through the development of tensile force in the horizontal members. Development of tensile force in beams requires a large deformation in the beam and the ability to create longitudinal restriction to balance this force.

This paper presents two procedures for evaluation of RC subassemblages under column removal scenario:

(i) First, it investigates the mechanisms of ALP by testing one scaled RC subassemblage and the results are compared with a full-scale model. Technical and economical constraints limit the use of full-scale specimens to study progressive collapse. This makes the possible use of scaled models of great importance. Understanding the behavior of scaled RC subassemblages under large deformations caused by column removal scenario, capability of scaled model in assessing progressive collapse, and comparison of scaled results with full-scale specimen are the objectives of this empirical research.

(ii) Then, a numerical study is also utilized in order to provide a better assessment of macromodels in progressive collapse analysis of RC subassemblages. The macromodel is first evaluated using experimental results in the literature; and next, the results of the scaled specimen are compared with validated numerical model. In addition, for further evaluation of capability in numerical model, six new subassemblages with different reinforcement and geometry are analyzed.

\section{Test Program}

This experimental study was performed as part of a research program to evaluate progressive collapse of structures at the Iran University of Science and Technology (IUST). The specimen included two single-bay beams, one middle joint, and two end columns with foundations. The full-scale test was performed by Lew et al. [5], and scaled specimen in this study was fabricated, instrumented, and loaded with materials and conditions nearly similar to the full-scaled specimen. The specimen was placed under middle joint point loading with displacement control and loading continued until complete failure of the specimen. During the experiment, the displacement and strain at predefined points and sections were measured and formation of resistance mechanisms and the failure mode were recorded.

2.1. Specimen Design. The details of the full-scale specimen have been provided in Lew et al. [5]. Figure 1 shows the plan of the prototype building. The building was designed as 10 stories for office occupancy and a concrete intermediate moment frame (IMF) system. The dead, live, and earthquake loads were determined according to ASCE7-02. The building was designed based on ACI codes and commentary (ACI 318R02) [16].

The selected subassemblage was a part of the exterior frame in axis 1 between axes $B$ and $D$ on the third floor. The scaled specimen is a $3 / 10$ scale model of the prototype intermediate moment frame (IMF). The scale of the specimen was selected to accommodate limitations on laboratory space, instrumentation, and access to bars with characteristics similar to those for full-scale test reinforcement. Figure 2 provides the details of the scaled specimen and shows that the top and bottom longitudinal bars in beam were anchored with a mechanical anchor to simulate continuity in external beamcolumn joints, as it is in the full-scale specimen. Because of symmetry, half of the specimen was shown in Figure 2. Longitudinal reinforcement of the columns was done by anchoring a $90^{\circ}$ hook inside the foundation $(700 \times 700 \times 300 \mathrm{~mm})$. To prevent sliding, the foundation was anchored to the laboratory strong floor using four threaded rods. A mechanical anchor for the main frame was used to prevent movement of the top of the columns towards the interior. Downward movement and rotation of the top of the column were kept free.

Table 1 shows the geometric characteristics of the fullscale and scaled specimens. The difference in percentage of reinforcement was caused by restrictions to access bars with characteristics similar to the prototype. Due to the short length of the scaled specimen, there is no need to splice the reinforcements. The average compressive and tensile strengths of the concrete were $26 \mathrm{MPa}$ and $1.5 \mathrm{MPa}$, respectively. The maximum size of the aggregate for the concrete was less than $10 \mathrm{~mm}$ to conform to the scale of the specimen. Beam and column longitudinal reinforcements were highyield strength rebars with $530 \mathrm{MPa}$ and $650 \mathrm{MPa}$ yield and ultimate strength, respectively. The ultimate strain of longitudinal reinforcement was 0.16 according to reinforcement tensile test.

The ratios of the top beam reinforcement at joints and at the beam mid span were considered to be $0.62 \%$ (3T8) and $0.41 \%$ (2T8), respectively. The ratio of the bottom beam reinforcement for the whole span was considered to be $0.41 \%$ (2T8). All stirrups had nominal diameter of $6 \mathrm{~mm}$ with two $135^{\circ}$ hooks. The stirrups were distributed with a center-tocenter spacing of $130 \mathrm{~mm}$ and $75 \mathrm{~mm}$ at mid span of the beams and at the beam ends, respectively. According to the expected ductile behavior of the specimen and the dominance of CAA, flexural action, and CA instead of shear behavior, the effect of size dependence on shear behavior could be neglected, Yu and Tan $[9,10]$ and Harris and Sabins [17].

2.2. Instrumentation. Figure 3 shows the layout of the linear variable differential transformers (LVDTs) used to measure displacement. Six LVDTs were used to measure vertical displacement of the beam at $1 / 4,1 / 2$, and $3 / 4$ of the beams span. Two LVDTs were used to measure central column displacement. Two LVDTs located at the sides of the beam measured any change in the length of the beam spans. Four LVDTs were used to measure horizontal and vertical displacement of the foundation. Two LVDTs measured probable horizontal 
TABLE 1: Geometric properties of prototype frames and specimens.

\begin{tabular}{|c|c|c|c|c|c|c|c|c|c|c|}
\hline \multirow[t]{2}{*}{ Specimen } & \multirow[t]{2}{*}{$\begin{array}{l}\text { Beam } \\
\text { span } \\
(\mathrm{mm})\end{array}$} & \multicolumn{2}{|c|}{ Beam size $(\mathrm{mm})$} & \multicolumn{2}{|c|}{ Column size $(\mathrm{mm})$} & \multirow[t]{2}{*}{$\begin{array}{l}\text { Reinforcement } \\
\text { ratio at the } \\
\text { column }\end{array}$} & \multicolumn{2}{|c|}{$\begin{array}{l}\text { Reinforcement } \\
\text { ratio at the } \\
\text { joint }\end{array}$} & \multicolumn{2}{|c|}{$\begin{array}{l}\text { Reinforcement } \\
\text { ratio at the } \\
\text { beam mid } \\
\text { span }\end{array}$} \\
\hline & & Depth & Width & Depth & Width & & Top & Bottom & Top & Bottom \\
\hline $\begin{array}{l}\text { Full-scale specimen } \\
\text { (prototype) }\end{array}$ & 5385 & 500 & 700 & 700 & 700 & $1.7 \%\left(12 \# 9^{* *}\right)$ & $\begin{array}{c}0.65 \% \\
\left(4 \# 8^{* *}\right)\end{array}$ & $\begin{array}{l}0.41 \% \\
(2 \# 9)\end{array}$ & $\begin{array}{l}0.32 \% \\
(2 \# 8)\end{array}$ & $\begin{array}{l}0.41 \% \\
(2 \# 9)\end{array}$ \\
\hline Scaled specimen & 1500 & 140 & 200 & 200 & 200 & $1.7 \%\left(12 \mathrm{~T}^{*} 8\right)$ & $\begin{array}{l}0.62 \% \\
(3 \mathrm{~T} 8)\end{array}$ & $\begin{array}{l}0.41 \% \\
(2 \mathrm{~T} 8)\end{array}$ & $\begin{array}{l}0.41 \% \\
(2 \mathrm{~T} 8)\end{array}$ & $\begin{array}{l}0.41 \% \\
(2 \mathrm{~T} 8)\end{array}$ \\
\hline
\end{tabular}

* "T" denotes high-yield strength reinforcement with nominal yield strength of $530 \mathrm{Mpa}$; T8: bar with $8 \mathrm{~mm}$ diameter.

** "\#” denotes high-yield strength reinforcement as referred in Lew et al., \#8: NO. 8 bar with $25.4 \mathrm{~mm}$ diameter, \#9: NO. 9 bar with $28.7 \mathrm{~mm}$ diameter.

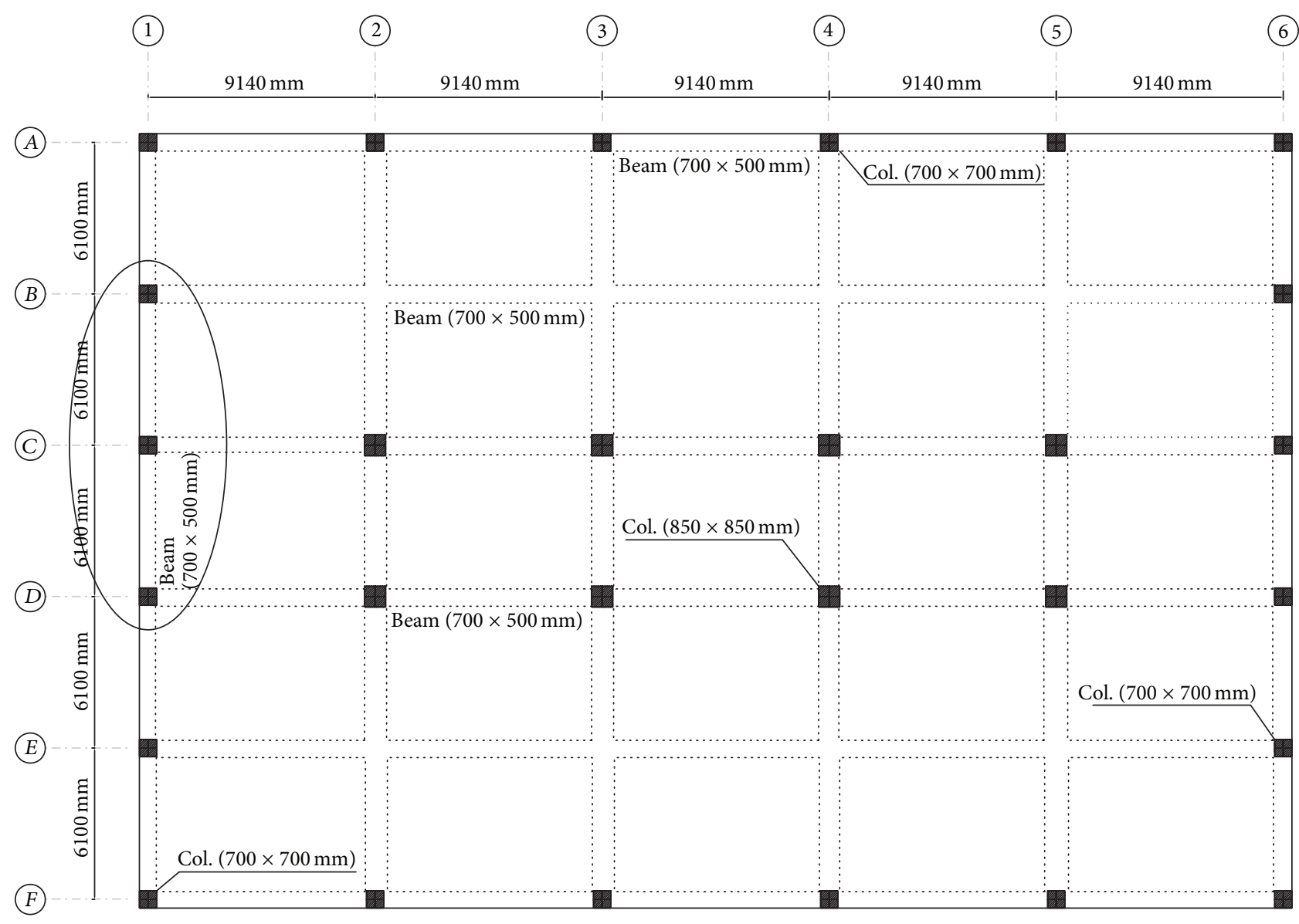

FIGURE 1: Plan layout of prototype building.

displacement at the top of the columns and one LVDT measured deformation of the loading frame.

Figure 4 shows arrangement of the strain gauges on the steel bars. Due to the geometric symmetry, one-half of the specimen for the location of strain gauges is shown. Uniaxial steel strain gauges were used on the reinforcing bars at specific locations to evaluate the internal forces and onset of the CAA and CA at different stages of loading. Five concrete strain gauges were placed on the beam surface at the middle and end connection interfaces. The force applied by hydraulic jack was measured by a load cell.
2.3. Test Setup and Loading. Figure 5 shows setup loading in the scaled specimen. The tops of both columns were connected to the loading frame using roller connections to prevent horizontal movement. Also the columns were free for vertical movement. The load was applied by hydraulic jack with displacement control on the middle column. Uniformly distributed load is more realistic in progressive collapse assessment of structure; however, a point-loading scheme is cost effective and safer in testing. A steel plate, $10 \mathrm{~mm}$ in thickness, was used at the top of the middle column to distribute the load from the jack and prevent the local stresses. 


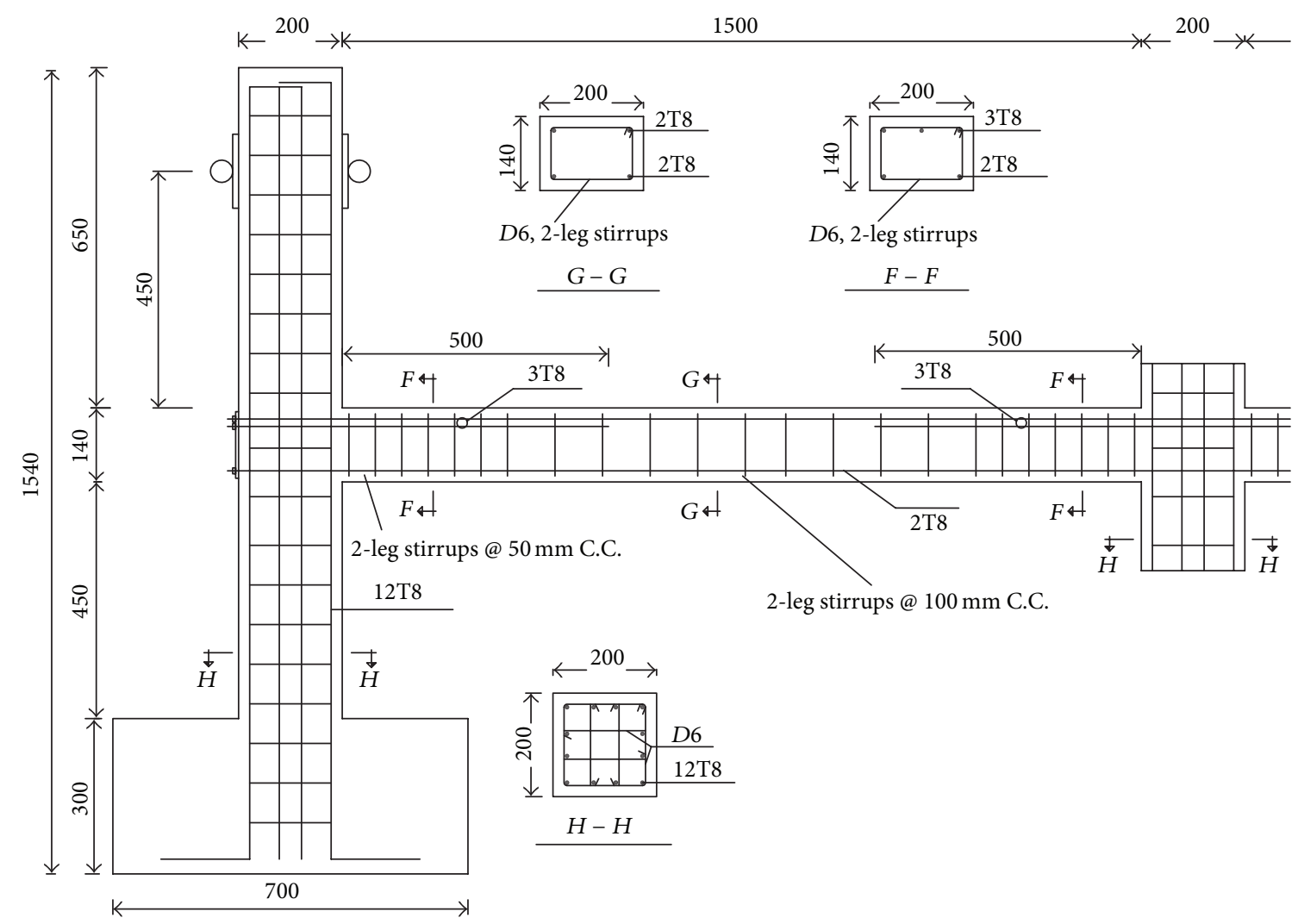

FIgURE 2: Details of the scaled specimen.

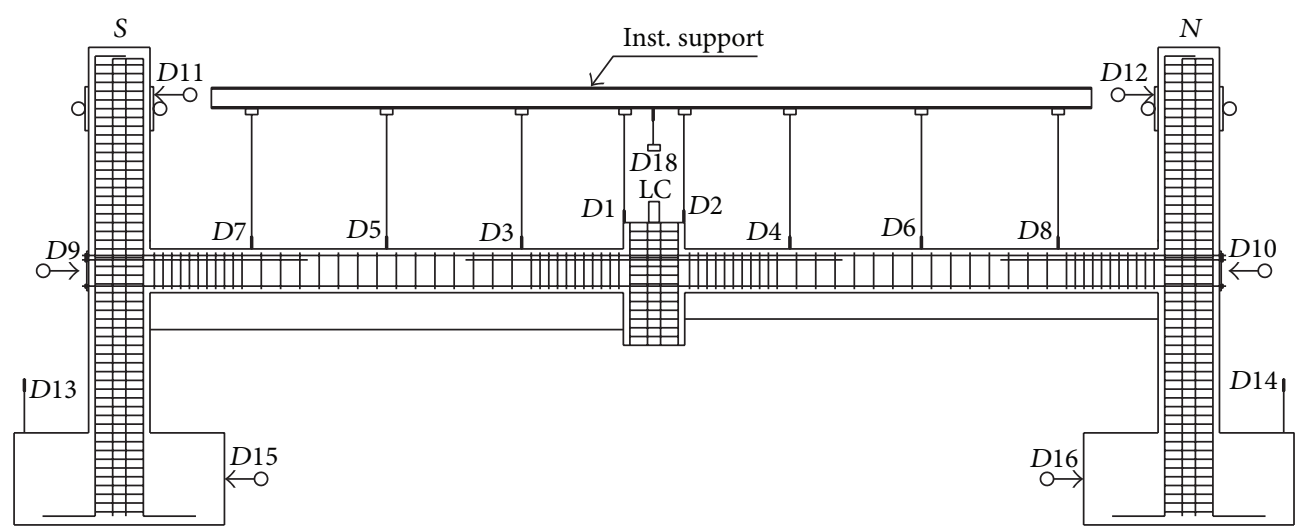

FIGURE 3: Layout of displacement measurements.

Vertical downward displacement of middle column was applied in small increments of $5 \mathrm{~mm}$ to $10 \mathrm{~mm}$. After each increment in displacement, the specimen was examined and cracks were marked.

Four steel channels (UPN 80) with section dimensions of $45 \times 8 \mathrm{~mm}$ (flanges) and $80 \times 6 \mathrm{~mm}$ (web) were attached to the loading frame and the laboratory floor to prevent out-ofplane displacement. To reduce friction between the specimen and channels, the surfaces of the channels and specimen were lubricated at probable contact sites.

\section{Test Results}

The specimen was placed under monotonic downward vertical displacement at the middle column until fracture occurred at the top reinforcement of the beam end. Concrete crushed at the top of the beam in the middle connection and flexural cracks developed throughout the depth of the beamcolumn interface. The test was terminated after the fracture of the beam top bar at vertical displacement of $306 \mathrm{~mm}$. Figure 6 shows fracture of bars in joints at the end of test. 


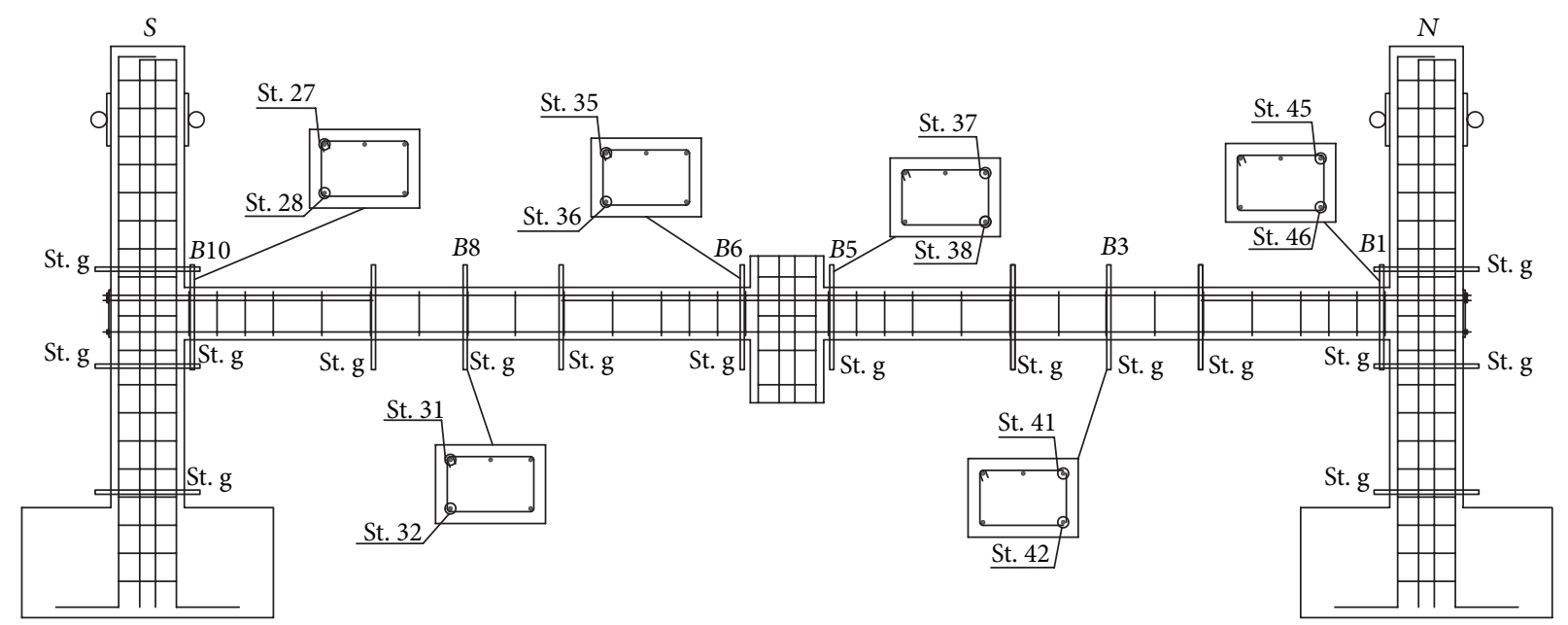

FIGURE 4: Layout of strain gauges reinforcement.

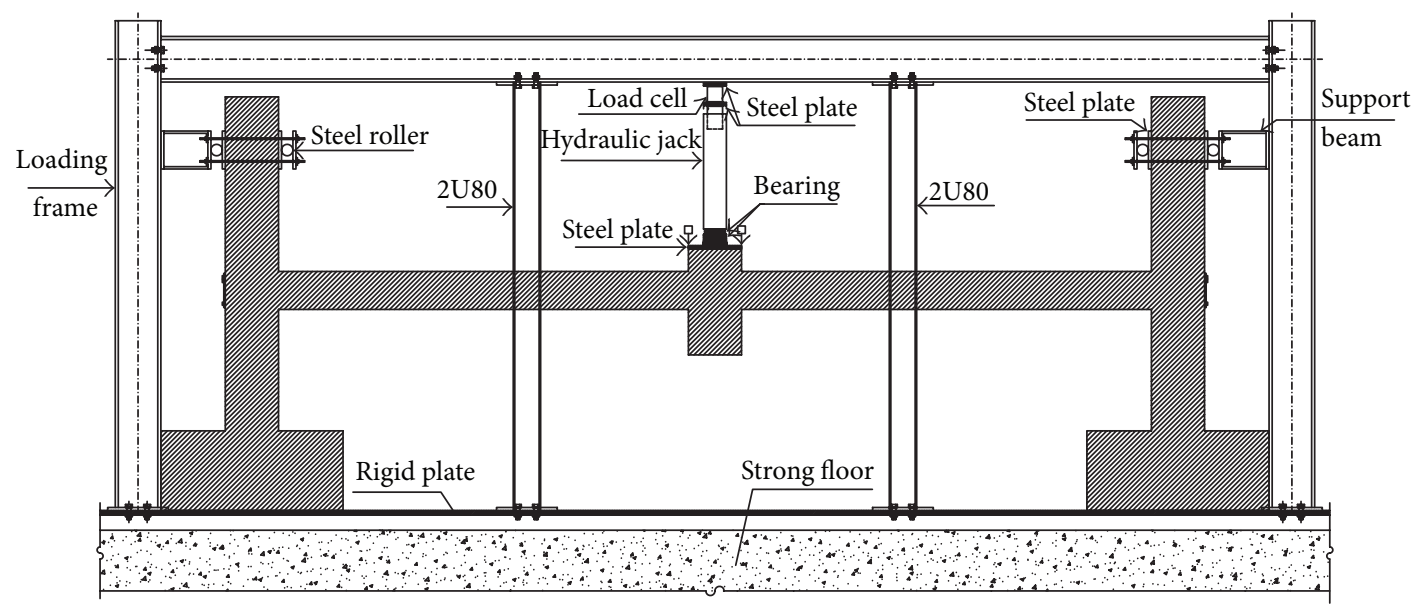

FIGURE 5: Setup of the test specimen.

3.1. Crack Patterns. Applying vertical displacement to the middle column caused flexural cracking along the beam. The main flexural cracks developed in the connection of beam to column. In vertical displacement of $25 \mathrm{~mm}$ equal to vertical load of $23 \mathrm{kN}$, inclined cracks developed at the beam-column joints in the end columns. As vertical displacement increased to $40 \mathrm{~mm}$, corresponding to vertical loading of $27 \mathrm{kN}$, more flexural cracks formed in the beams and shear cracks started to develop in the bottom of the columns.

As vertical displacement of the center column increased to $110 \mathrm{~mm}$ with a vertical load of about $21 \mathrm{kN}$, concrete crushing occurred in the areas of the beams subjected to high compression near the middle column and the bottom of the beams at both ends. By the end of this stage, the main flexural cracks became deeper at the ends of the beams and were up to $90 \%$ of the total height of the beams.

The bottom bar of south beam adjacent to the middle column fractured after vertical displacement of $170 \mathrm{~mm}$. When vertical displacement increased to $230 \mathrm{~mm}$, the other bottom bar at this place fractured. With further displacement of middle column, the top bar at the south end of the beam fractured and test was halted. Full-depth cracks in the beam-column interface and in the middle of the beams were visible at this time. Figure 7 shows the crack pattern in the south end at the end of the test.

Figures 8 and 9 show the comparison of crack pattern in scaled and full-scale specimens. Figure 8 compares crack pattern in the vertical displacements of middle joint equal to 1.2 times the beam height $(170 \mathrm{~mm}$ for scaled specimen before rebar fracture and $610 \mathrm{~mm}$ for full-scale specimen) and Figure 9 compares the final crack patterns.

A comparison of crack pattern for the full-scale and scaled specimens shows that the crack patterns and location of the main cracks are similar. Despite this overall similarity, the number of cracks in the columns and connection were much fewer in the scaled specimen than in the full-scale specimen. In the full-scale specimen, more cracks were distributed along the beams, but considerably fewer cracks were observed in the scaled specimen. Based on experimental studies reported in Harris and Sabins [17], beams with smaller heights subjected to similar flexural loading have higher strain gradients, which lead to higher ultimate tensile strain. 


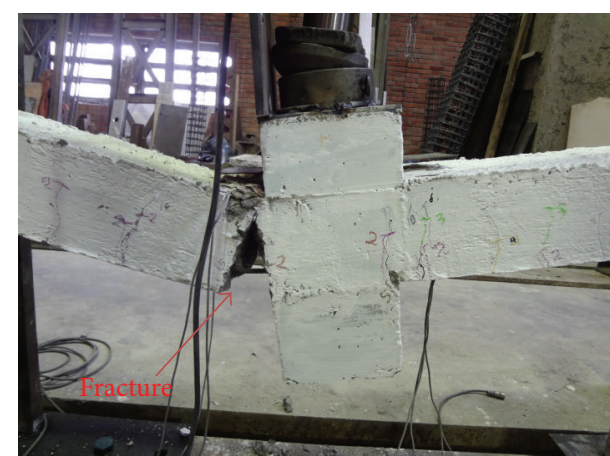

(a) Middle joint

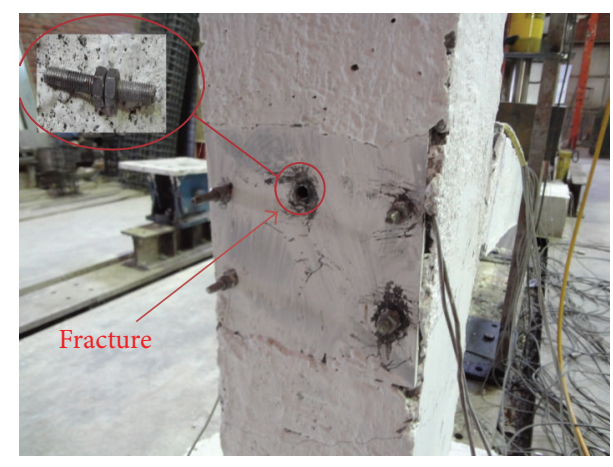

(b) End joint

Figure 6: Fracture of bars. (a) Middle joint. (b) End joint.
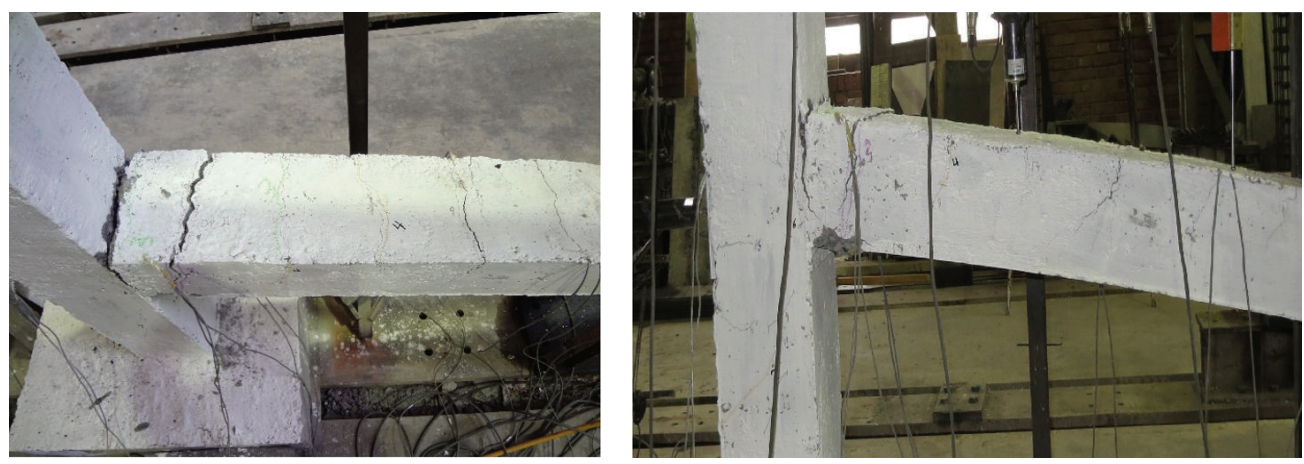

FIGURE 7: Crack pattern in south end of the specimen.

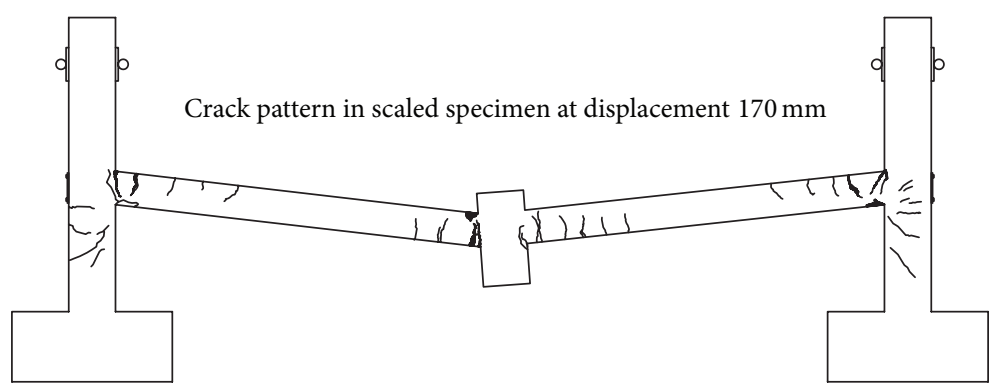

(a)

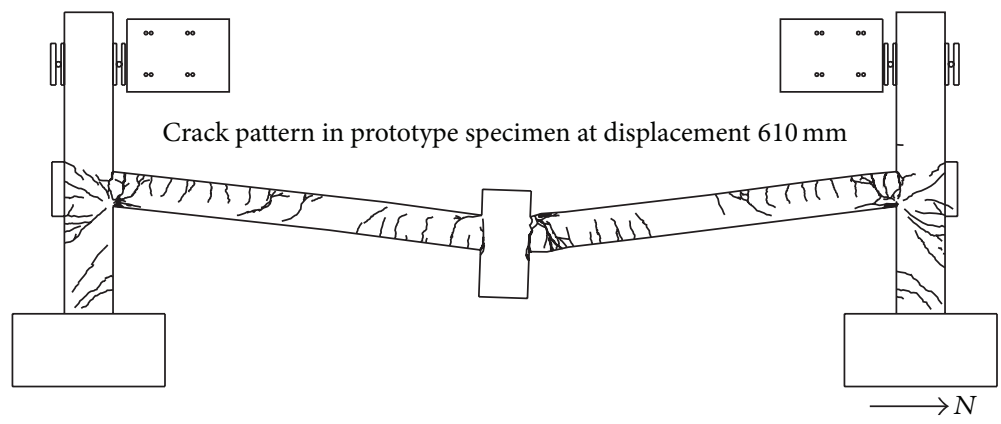

(b)

Figure 8: Comparison of crack pattern in full-scale and scaled specimens at vertical displacements of middle joint equal to 1.2 times the beam height. 


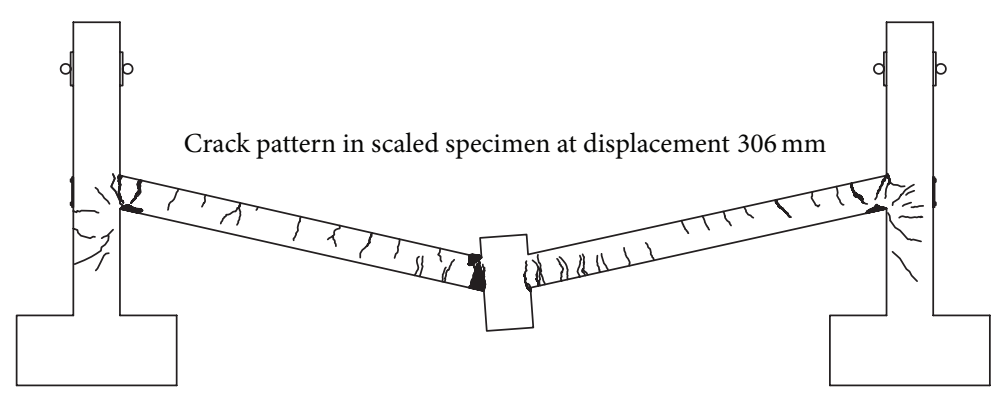

(a)

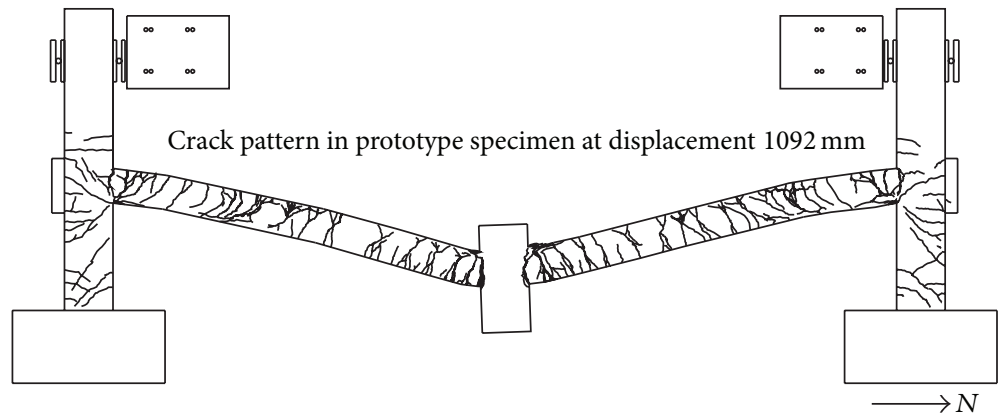

(b)

FIGURE 9: Comparison of crack pattern in full-scale and scaled specimens at the end of tests.

Hence, this can be a justification for differences in crack pattern in scaled specimen compared to full-scale specimen. In addition, dissimilarities of material properties, higher tensile strength in concrete with smaller aggregate size, and the effect of strain gradient as stated earlier can justify the differences in crack pattern.

Fracture of the rebar at the south face of middle joint caused main cracks in this region to develop. As cracks were developed more in one side of the joint, middle connection started to rotate. The rotation of middle connection in the scaled specimen is more severe in comparison to the full-scale specimen, which can be seen in Figure 9.

3.2. Load-Displacement Curve. Figure 10 shows the vertical load versus vertical displacement of the middle connection. In order to compare the general behavior of scaled and fullscale specimens, load-displacement curve of scaled-down prototype is also shown in Figure 10. For scaling down the prototype results, a dimensional analysis was utilized. Based on Buckingham's theorem, the following quotient can be formed:

$$
\frac{\pi_{1 p}}{\pi_{1 m}}=\frac{\emptyset\left(\pi_{2 p}, \pi_{3 p}, \ldots, \pi_{n p}\right)}{\emptyset\left(\pi_{2 m}, \pi_{3 m}, \ldots, \pi_{n m}\right)},
$$

where $\pi_{i p}$ and $\pi_{i m}$ are dimensionless products of the prototype and model, respectively. Complete similarity leads to

$$
\pi_{i p}=\pi_{i m} .
$$

The scaling factor for concentrated load, stress, and moment, respectively, can be presented as follows:

$$
S_{\mathrm{Q}}=S_{E} \cdot S_{l}^{2},
$$

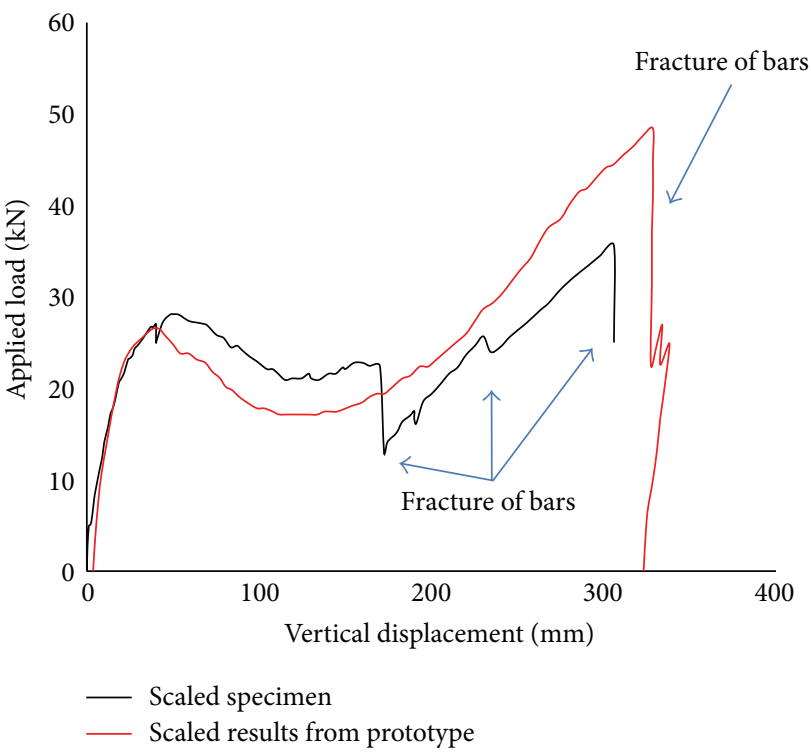

Figure 10: Comparison of results from scaled specimen and scaled results from prototype.

$$
\begin{gathered}
S_{\sigma}=S_{E}, \\
S_{M}=S_{E} \cdot S_{l}^{3},
\end{gathered}
$$

where $S_{E}$ and $S_{l}$ are scaling factor for elasticity and geometry, respectively. Because reinforcing dominate the behaviors in doubly reinforced beams, scaling factor for modulus of elasticity is equal to 1 . 
TABLE 2: Comparison of force and displacement at critical points of scaled specimen and scale-down results of prototype.

\begin{tabular}{|c|c|c|c|c|c|c|c|c|}
\hline \multirow[b]{2}{*}{ Specimen } & \multicolumn{2}{|c|}{ Flexural action } & \multicolumn{2}{|c|}{ Compressive arch action } & \multicolumn{2}{|c|}{ Beginning of catenary action } & \multicolumn{2}{|c|}{ Catenary action } \\
\hline & $\begin{array}{c}P(\mathrm{FA}) \\
\mathrm{kN}\end{array}$ & $\begin{array}{c}Y(\mathrm{FA}) \\
\mathrm{mm}\end{array}$ & $\begin{array}{c}P(\mathrm{CCA}) \\
\mathrm{kN}\end{array}$ & $\begin{array}{c}Y(\mathrm{CCA}) \\
\mathrm{mm}\end{array}$ & $\begin{array}{c}P 0(\mathrm{CA}) \\
\mathrm{kN}\end{array}$ & $\begin{array}{c}Y(\mathrm{CA}) \\
\mathrm{mm}\end{array}$ & $\begin{array}{c}P(\mathrm{CA}) \\
\mathrm{kN}\end{array}$ & $\begin{array}{c}Y(\mathrm{CA}) \\
\mathrm{mm}\end{array}$ \\
\hline Scaled specimen & 20.7 & 18.5 & 28.1 & 50 & 21 & 135 & 35.6 & 306 \\
\hline $\begin{array}{l}\text { Scaled-down results } \\
\text { from prototype }\end{array}$ & $\begin{array}{l}\text { Not } \\
\text { reported }\end{array}$ & $\begin{array}{c}\text { Not } \\
\text { reported }\end{array}$ & 26.6 & 38.1 & 17.64 & 122 & 49.2 & 339 \\
\hline Difference\% & - & - & 5.6 & 31.2 & 19 & 10.7 & 38.2 & 10.8 \\
\hline
\end{tabular}

As plotted, the specimen developed three stages of alternative load path including flexural action (FA), Compression Arch Action (CAA), and catenary action (CA), despite bar fracture at early stage of CA. At a vertical displacement of $50 \mathrm{~mm}$, the load reached an initial peak of $28.1 \mathrm{kN}$ which corresponded to CAA capacity of subassemblage. As displacement increased, the vertical load decreased and started to increase again at a displacement of $135 \mathrm{~mm}$, which corresponded to a vertical load of $20.9 \mathrm{kN}$. Applying more displacement caused the fracture of the first rebar at the middle joint at displacements of $170 \mathrm{~mm}$ which caused a sudden drop in the load from $22.4 \mathrm{kN}$ to $12.9 \mathrm{kN}$. With increasing the displacement, the load started to increase again until the fracture of second bottom bar occurred at displacement of $230 \mathrm{~mm}$ and load value of $25.7 \mathrm{kN}$. Applying load was stopped with the fracture of one of the beam top bars at the south beamcolumn connection at displacement of $306 \mathrm{~mm}$ and load value of $38.2 \mathrm{kN}$, which attained a maximum for CA capacity.

Comparison of scaled and full-scale specimens shows that, despite bar fracture at scaled specimen in the early stage of CA, general behaviors are similar. In the first stage of loading curve, both curves are almost identical until they reached their CAA capacity. Approximately linear behavior of material and less and small cracks in concrete in this stage can be a justification for this similarity in this region of load-displacement curves. Beyond vertical displacement of $38 \mathrm{~mm}$, the load in scaled-down curve from full-scale specimen started to decrease whereas in test specimen of this research, the load continued to increase up to displacement of $50 \mathrm{~mm}$. Generally, from displacement of $38 \mathrm{~mm}$ to $170 \mathrm{~mm}$, the graph of the scaled specimen is above the scaled-down results of the full-scale specimen. As mentioned earlier, because of relatively high strain gradient in addition to larger yielding strength of reinforcing steel in scaled specimen, the flexural strength of scaled specimen is higher than the predicted value from scaling. Also less cracks in scaled specimen lead to relatively high stiffness of the specimen against vertical load. It should be noted that, for the full-scale specimen, the failure criterion was the fracture of bottom bar in middle connection. Hence, the bottom bar participated in the CA capacity up to collapse of the specimen. In scaled specimen, because of bottom bar fraction, only top bars strength participates in CA capacity of the subassemblage beyond vertical displacement of $230 \mathrm{~mm}$.

Table 2 shows comparison of results for scaled specimen and scaled-down results of the full-scale specimen. Due to the lack of flexural action results for the full-scale specimen, the comparison could not be done in this stage. However, numerical comparison of CAA and CA stages for both scaled and scaled-down results of the full-scale specimen is given in Table 2. Figure 10 and Table 2 show that scaled specimen also has the ability to estimate progressive failure of subassemblage, but with lower cost.

Table 3 shows the forces and displacements at critical points in the load-displacement curve of scaled specimen. The bottom reinforcement at the middle joint yielded quickly at the onset of loading. Yielding of the top beam reinforcement at its two ends created plastic hinges in the beams. The nominal flexural capacity of the beam was calculated based on conventional plastic mechanisms. Corresponding analytical load and displacement are shown in Table 3. According to the results, the experimental flexural capacity was greater than the calculated nominal flexural capacity. This has occurred because of the development of the compressive force in the beams, even at the initial stages of loading. CAA increased structural strength to $36 \%$ over flexural capacity and displacement corresponding to CAA was $33 \%$ of the height of the beam.

Fracture of the bottom rebars in beam eliminated flexural resistance in the middle joint. The tensile force acted as the only resisting mechanism in the specimen. The onset of CA occurred simultaneously with fracture of the second beam bottom reinforcement at a vertical displacement of $230 \mathrm{~mm}$, which corresponds to 1.53 times the beam height. Maximum CA capacity was achieved only through the top beam reinforcements. CA enhanced structural resistance by about $80 \%$ compared to flexural action.

Table 3 shows the capacity of CA based on the simple analysis proposed by Jian and Zheng [18] and Yu and Tan [10]. As presented in Figure 11, horizontal and vertical equilibrium equations for the beam axial force resulted in

$$
P_{\mathrm{CA}}=\frac{2 \cdot T_{u} \cdot y_{\mathrm{CA}}}{l}
$$

where $T_{u}$ is the tensile resistance, $y_{\mathrm{CA}}$ is the middle joint vertical deflection that corresponds to CA capacity, and $l$ is effective spans of beams.

In the technical literature $y_{\mathrm{CA}}$ was adopted as $10 \%$ of the total two-bay beam span length. Hence, (6) can be expressed as

$$
P_{\mathrm{CA}}=0.4 T_{u}
$$

Tensile strength of the beam in the final stages of loading is produced only from reinforcement. Examination of several 


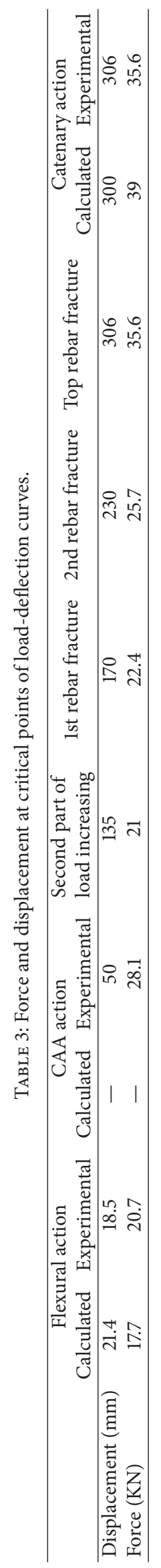




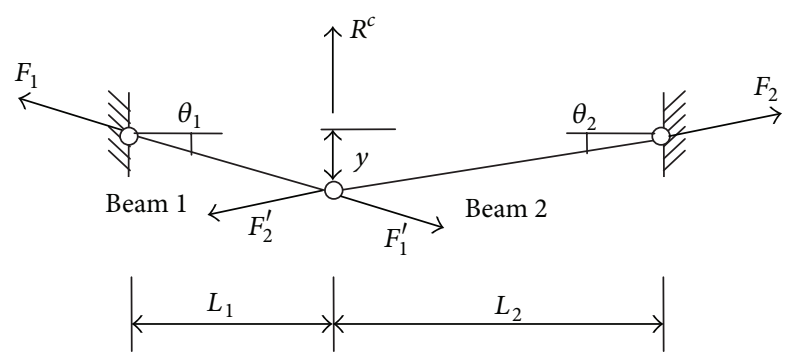

FIGURE 11: Force equilibrium diagram in CA stage [18].

structural experiments has shown that tensile resistance can be computed with consideration of only top reinforcement bars at middle joint. In specimen with similar behavior of this research, due to the fracture of bottom reinforcement, this assumption is correct. Bottom reinforcements in joints, due to the negative flexural moment, are less than top reinforcements at two sides of a joint under normal design conditions. In addition, at both sides of middle joint wide cracks develop in the catenary action stage that leads to stress concentration and bar fractures (Yi et al. 2008 [6], Lew et al. 2014 [4], and Yu and Tan 2013 [10]). Since bottom bars are less than top, mostly the fracture occurs at bottom bars. In specimens where bottom reinforcement determines the behavior in catenary action phase, this assumption can be used with a justification. Beyond tensile force capacity of top reinforcement, the fracture of bottom reinforcement consequently leads to fracture of top reinforcement and collapse of specimen. Hence, it is rational to consider the CA capacity with consideration of top bars as only resisting elements. Thus, (7) can be expressed as

$$
P_{\mathrm{CA}}=0.4 A_{S_{\mathrm{top}}} \cdot f_{u_{\mathrm{top}}} .
$$

There was little difference between the calculated values and the results obtained from the test for CA capacity for scaled specimen. Fracture of the top beam bar occurred at a value between yield and ultimate strength in response to the stress concentration at the middle and end joint interfaces.

3.3. Deflection Profile. The deflection profile of the specimen at the different steps of loading is shown in Figure 12. Deflection profile was estimated with line between two points of measurement. The deflection profile in small displacement is symmetrical, but possible middle joint rotation and the concentration of main flexural cracking in the south side of the middle joint created a beam deflection profile asymmetric for large deflection. Profile deflections of scaled and fullscaled specimens are similar according to [5]. Moreover, due to the rotation of the middle joint, unsymmetrical profile has occurred for scaled specimen.

3.4. Strain in Beams. Figure 13 shows the strain in the reinforcements at mid span of the north and south beams. As seen, under vertical displacements of less than $115 \mathrm{~mm}$, both the top and bottom bars showed negative (compressive) strain which indicates the development of compressive force in the beams during this stage. As displacement increased from $115 \mathrm{~mm}$ to $200 \mathrm{~mm}$, the strain in the reinforcement and axial

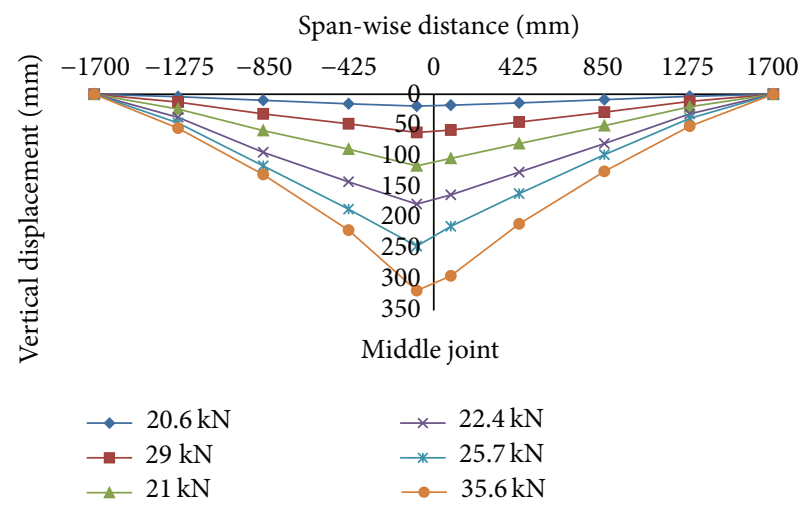

FIGURE 12: Deflection profiles of specimen corresponding to indicated loads.

force of the beams gradually changed from compression to tension. At vertical displacement greater than $200 \mathrm{~mm}$, all rebars at mid span showed positive (tensile) strain, which clearly indicates the development of tensile force in the subassemblage.

\section{Numerical Analysis}

Experimental and analytical studies by Bao et al. [3], Lew et al. [4, 5], Lowes et al. [19], and Mitra and Lowes [20] revealed the importance of the connections to the behavior of structural systems. Nonelastic behavior in numerical analysis was limited to flexural yielding of beams and columns.

In this paper, Opensees software [21] was used to analyze the behavior of subassemblage in the column removal scenario. First, numerical model was validated using experimental tests in literature [5]. Then, with validated numerical model, the results of scaled specimen were compared to the numerical results. In addition, for further evaluation of progressive collapse of subassemblages, six new models were introduced and analyzed using the validated numerical model.

4.1. Modeling Approach. For nonlinear behavior of elements, a displacement-based fiber element that exists in the software library was used. Analytical and experimental studies have shown that the shear behavior of frame elements in progressive collapse is not the dominant overall behavior of the structures. Hence, in spite of some shear cracks in the experiment of this research, it was ignored and displacement-based fiber elements were selected for modeling of RC beam-column subassemblages.

The joint element introduced by Altoontash [22] was used to examine the behavior of the connections. The joint model has one rotational spring for the shear behavior of the connection and four rotational springs for the beamto-column join interface. Figure 14 shows the configuration of the joint element idealized as parallelogram shaped shear panel. The beam and column elements are connected to the joint elements via four external nodes at the mid point sides of the parallelogram. The parallelogram shape in the analysis is held by kinematic constraints between external nodes and 


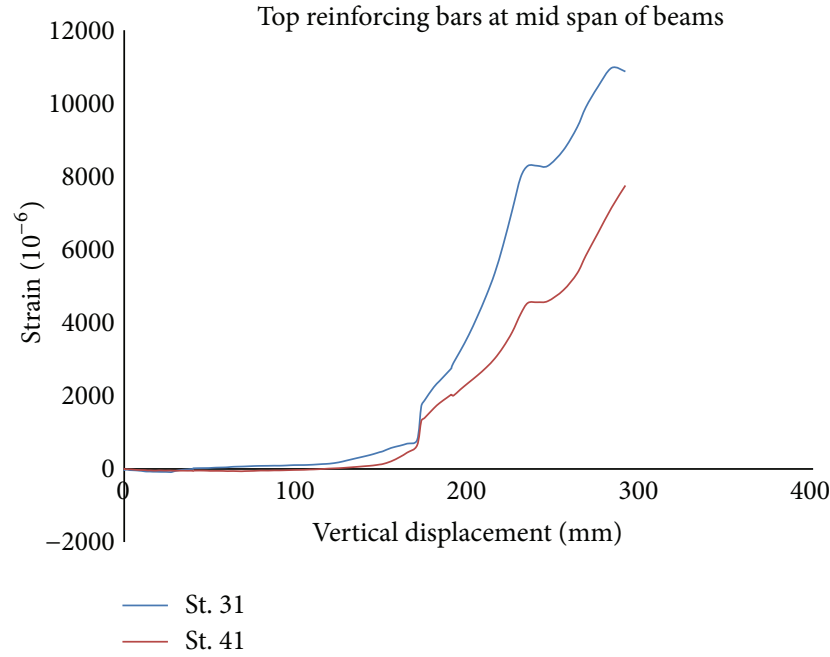

(a)

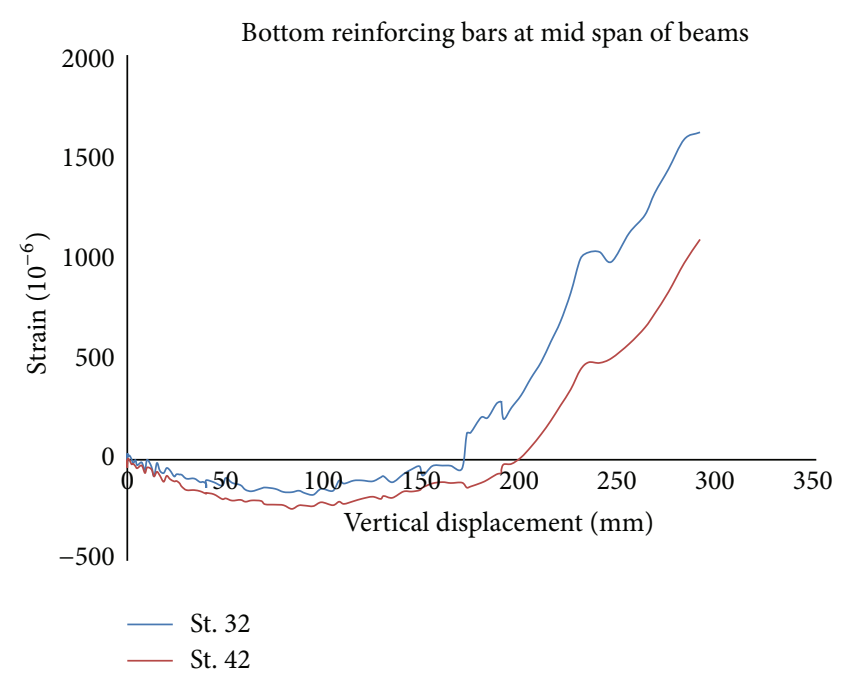

(b)

FIGURE 13: Strain in bars at beam mid span versus vertical displacement of middle joint.

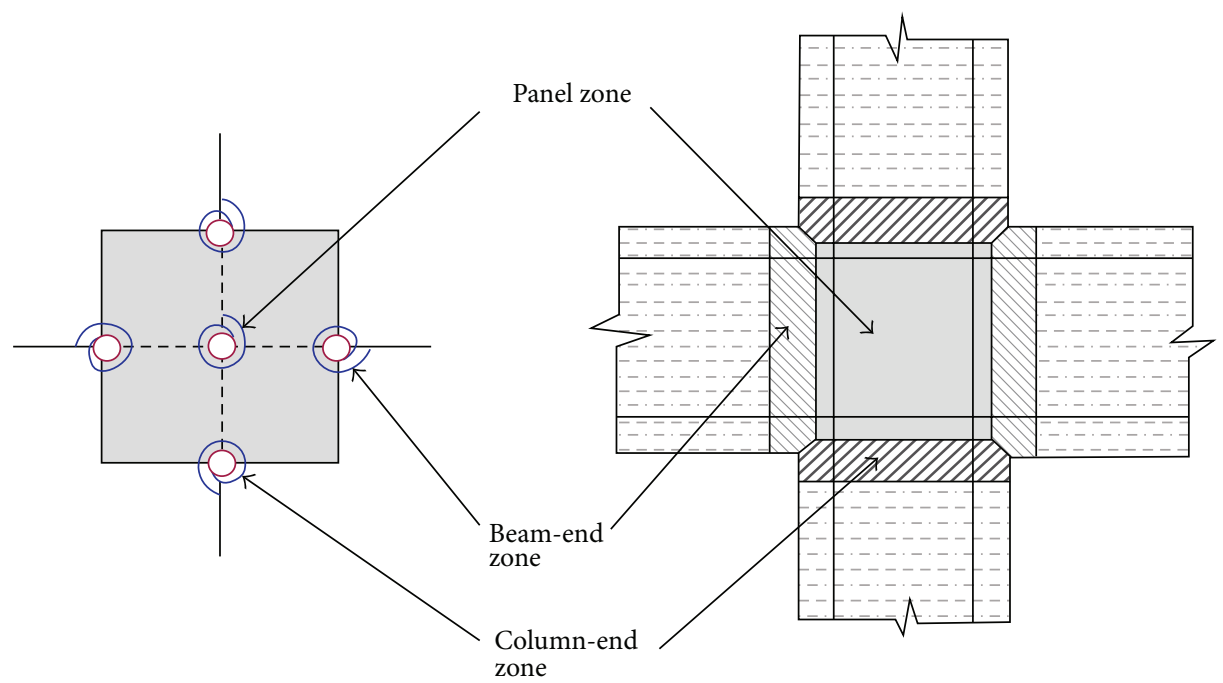

FIgURE 14: Configuration of the joint element [22].

the central node. Further details can be found in McKenna et al. [21].

Investigation of several experimental studies shows that, because of noncyclic nature of loading in a progressive collapse, shear panels also remain intact and bar fractures at the middle joints are the main failure mode of the structures. In addition to some specimens bar-slip affected the responses of the substructures. In this research, to calculate the material properties for the rotational springs of the joint model, the behavior of shear panel and joints interface are considered. The membrane 2000 program based on MCFT theory was used to calculate properties of shear panel springs [23]. Moment-rotation relation for in-plane shear panel of the tested specimen is plotted in Figure 15(a).

The properties of the spring in the middle joint are attained by putting bar-slip formulation in the configuration of bilinear steel material for moment curvature analysis of beam and column sections at joints. The results of the analysis in sections are used to define trilinear uniaxial materials in order to represent the member end rotation spring properties.

Figure 15(b) presents member end rotation spring for scaled specimen of this study. The fracture of bar is considered by using "Min-Max" material in Opensees. This material fails if maximum strain in steel material falls above certain threshold values. Shear behavior of beam-joint interface is modeled by zero length elements with elastic material. Figure 16 shows a numerical model of the tested subassemblage.

4.2. Calibration of Model. Full-scale laboratory tests by Lew et al. [4] were used to calibrate numerical model. Two specimens, intermediate moment frames (IMF) and Special Moment Frames (SMF), were designed and tested under monotonic downward loading in their research [4]. Figure 17 


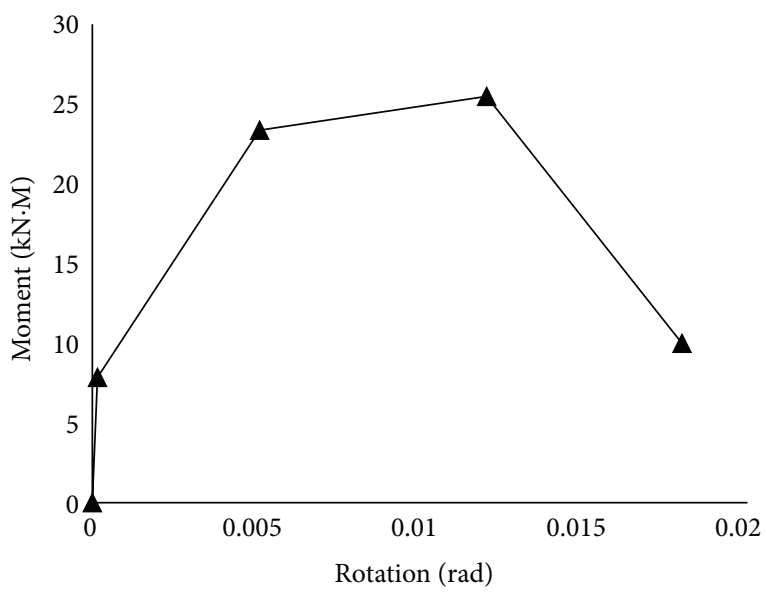

(a) Shear panel spring

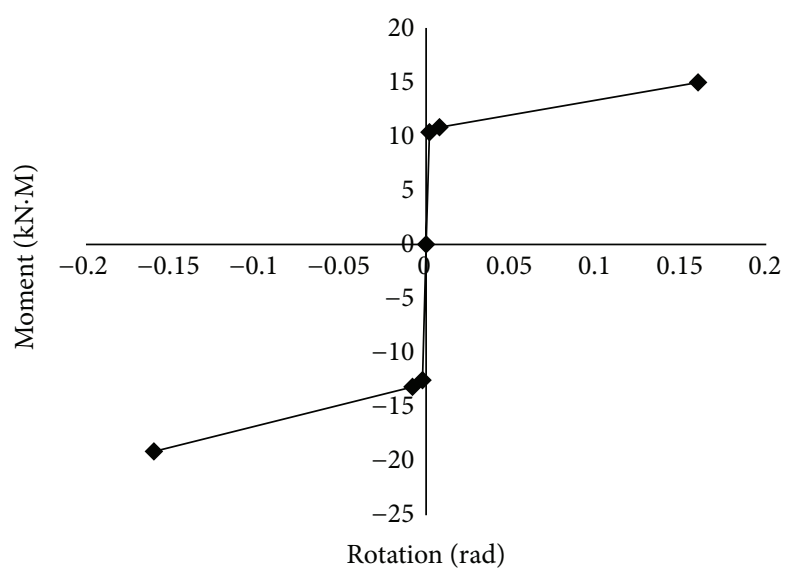

(b) Interface spring

FIGURE 15: Spring properties of joint element for the scaled specimen.

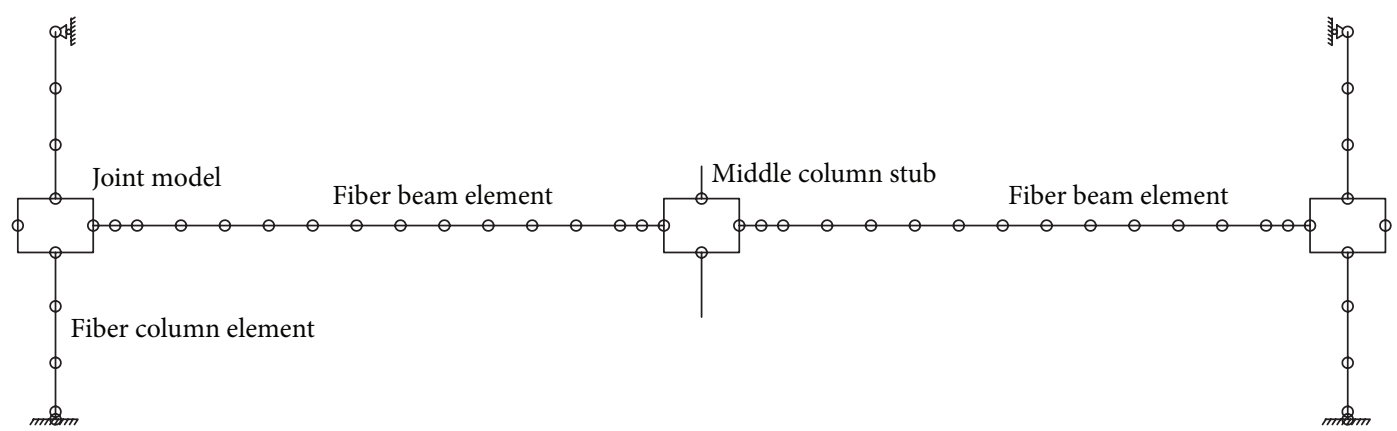

FIGURE 16: Numerical model of subassemblage.

shows the numerical and experimental load-displacement curves of middle column in the IMF and SMF specimens, respectively. The results of the numerical model with end offsets and rigid connection behavior are also presented. As seen, there is a good agreement between the numerical and experimental results. Ignoring the connection behavior caused up to $30 \%$ overestimation of the bearing capacity in the CAA capacity in the numerical model.

4.3. Results of Numerical Model. By validation of numerical model, the load-displacement curves from experimental test and the numerical model for scaled specimen are shown in Figure 18. As seen, the numerical model appropriately predicted the behavior of the subassemblage. In addition, for investigation of the effect of boundary conditions on the behavior of subassemblage, the result of numerical model with fixed ends is also presented in Figure 18.

Figure 19 shows beam axial force versus vertical displacement of middle joint. The beam axial compression force increased up to vertical displacement of $50 \mathrm{~mm}$ and then it started to decease. In vertical displacement of $195 \mathrm{~mm}$, beam axial force changed from compression to tension and was evident for development of tensile force in the beams of subassemblage. Similar to the load-displacement curve, for investigating the effect of boundary conditions on beam axial force, the result of numerical model with horizontal restriction of both ends is also presented in Figure 19.

Horizontal displacements of end columns at the beam mid heights are plotted in Figure 20. As seen, generally experimental and numerical results have good agreement especially before the fracture of bars. In the last part of the curves, different failure mechanisms of the experimental and numerical model lead to differences in the results.

Stress results at mid span for top and bottom bars are shown in Figures 21 and 22. Generally, the development of stress in the numerical model is the same with experimental scaled specimen. However, the absolute value of stresses cannot be modeled because of discrepancies of material properties and stress concentrations in the experimental program.

4.4. Parametric Study with Validated Numerical Model. To evaluate the effect of reinforcement percentage and geometry on the load-displacement curve, a parametric study was also conducted in this study. Six new models with similar characteristics of IMF specimen (full-scale) but with different reinforcement in beam or geometry were analyzed. The objective of this study is to show the capability of numerical model in order to attain response of structure with different details of reinforcement and geometry. 


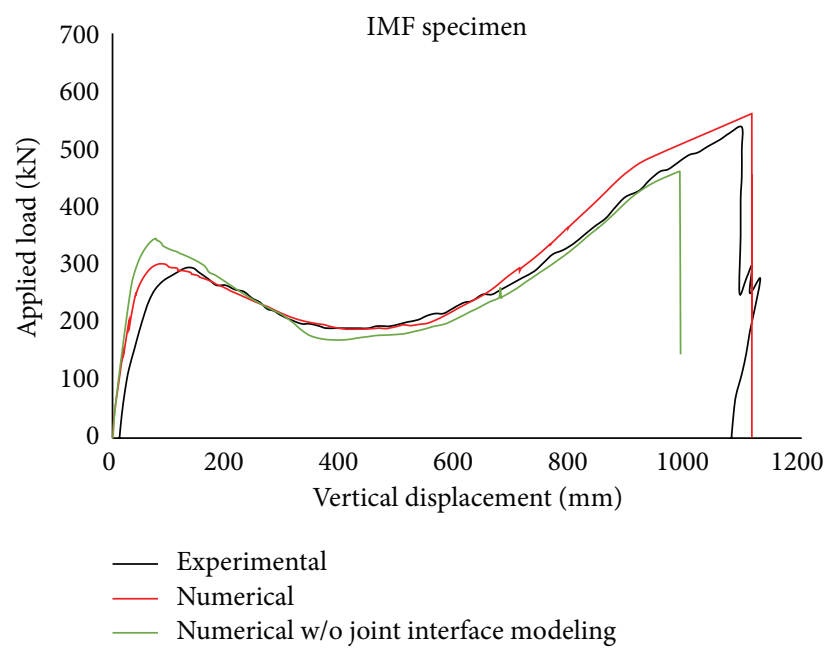

(a)

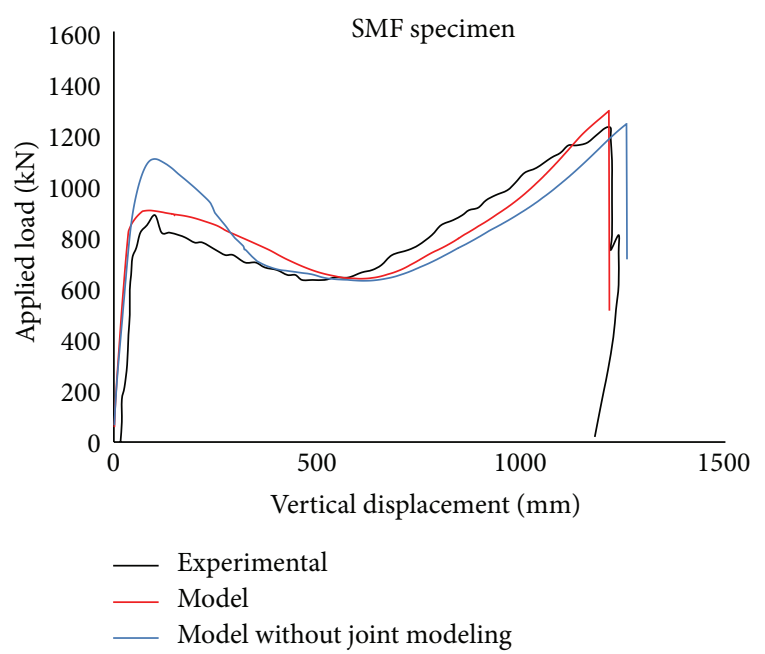

(b)

FIGURE 17: Numerical and experimental load-deflection results for IMF and SMF specimens.

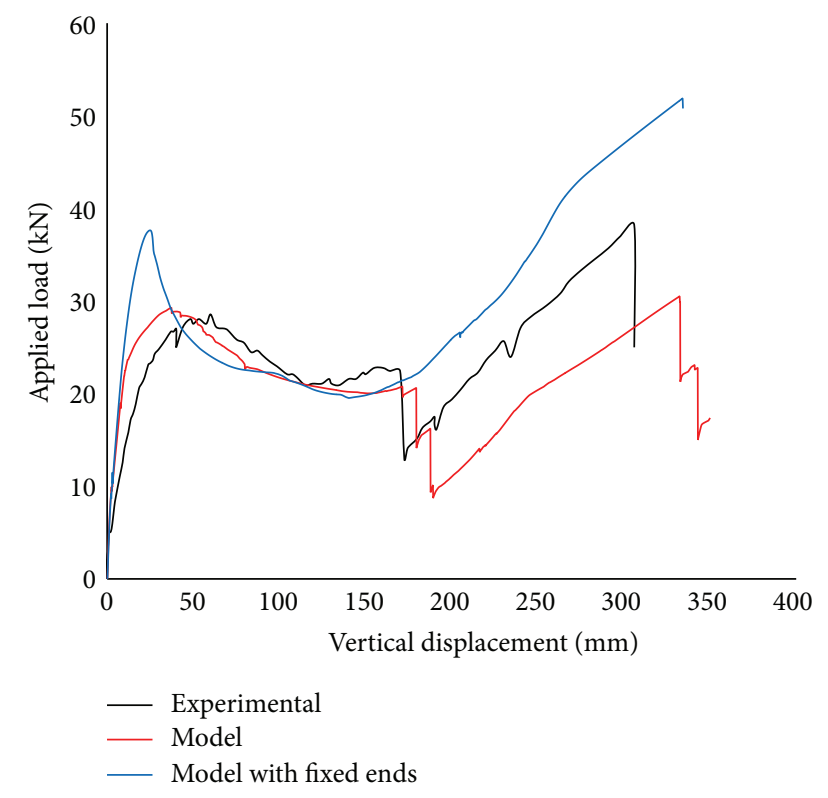

FIGURE 18: Numerical and experimental load-deflection results of the scaled specimen.

4.4.1. Effect of Reinforcement Percentage. Details of reinforcement in beams are presented in Table 4 . The reference model is IMF specimen (full-scale specimen), which is referred to as M1 here, and is the benchmark model. Hence, the results of other models (M2 to M5) would be compared to M1. In the M5 model, the top and bottom reinforcement were similar to $\mathrm{M} 1$ model. For improving the response of specimen, half of minimum reinforcements, which were defined in the ACI 318 , were added in the mid height of the beams. Figure 23 shows the load-displacement results of M1 to M5. As shown in Figure 23, generally increasing both top and bottom reinforcements and top reinforcement singly caused the improvement of capacity in all stages of load carrying mechanisms.

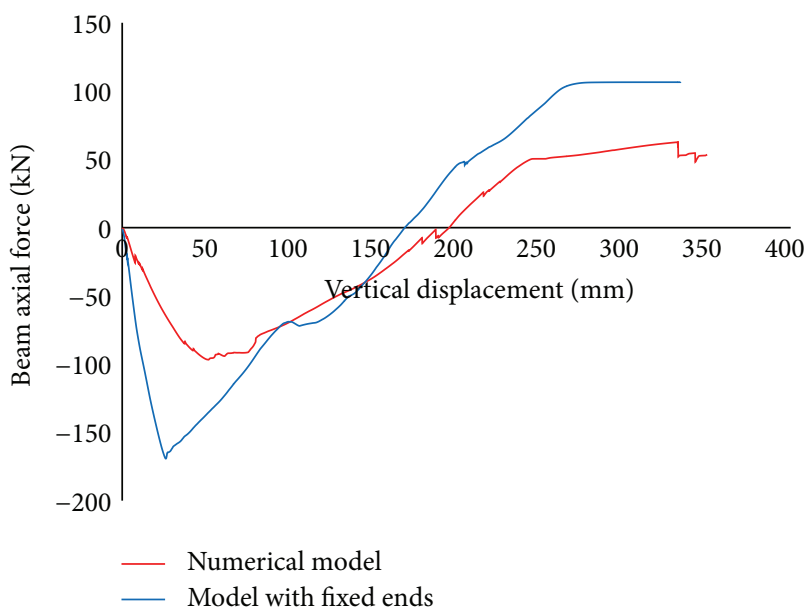

FIGURE 19: Comparison of beam axial force in numerical model with and without fixed ends.

Increase of the bottom reinforcement enhanced the response mainly in arc action stage (before CA stage) but caused a sudden drop in load-displacement response afterwards.

As represented in Figure 23, increasing reinforcement in mid height of the beam significantly improves the behavior of the structure.

4.4.2. Effect of Geometry. To investigate the effect of beam geometry on the progressive collapse behavior, two models with different beam height were also analyzed. The details of models are identical with IMF specimen (M1 model), but with 600 and $700 \mathrm{~mm}$ beam height for M6 and M7, respectively. For each model, minimum reinforcement of flexural members as specified in ACI 318 was considered. The loaddisplacement curves of M6 and M7 are plotted in Figure 24. The beam with deeper height significantly had greater capacity in beam action stages especially in CAA stage of resisting 


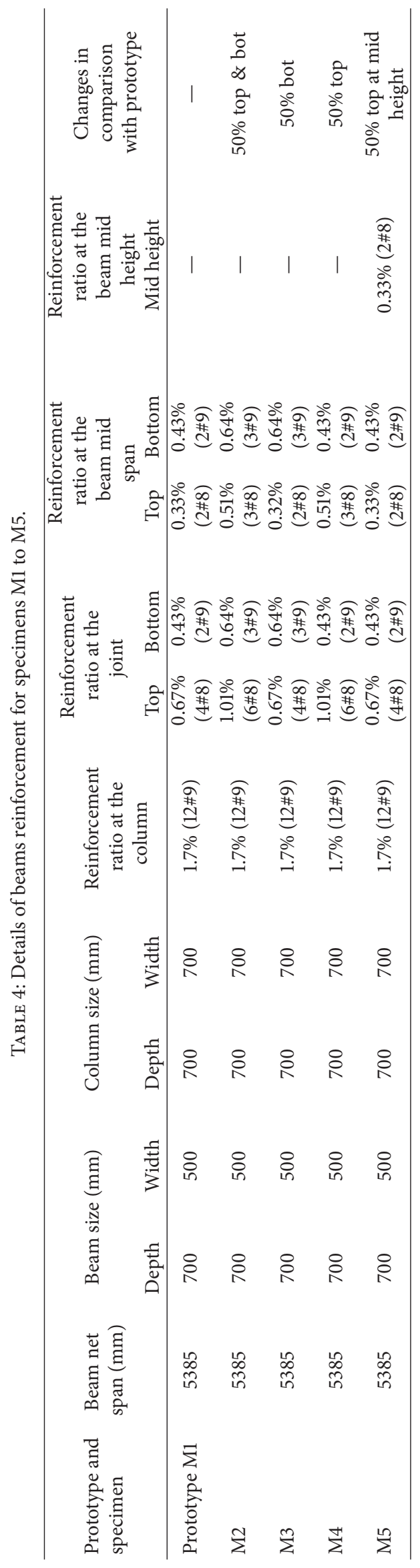




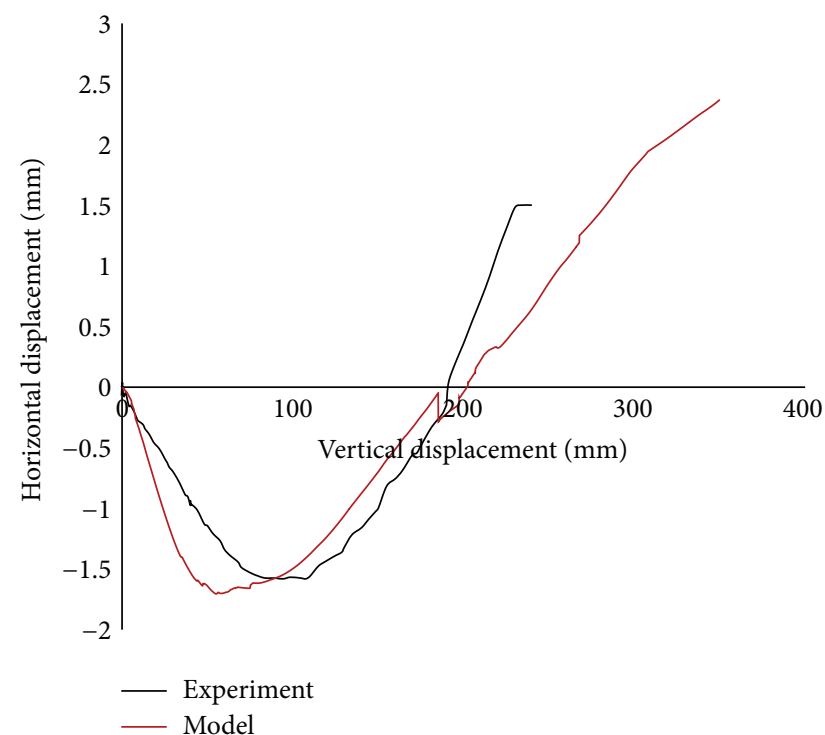

FIGURE 20: Horizontal displacement of end columns versus vertical displacement of center column.

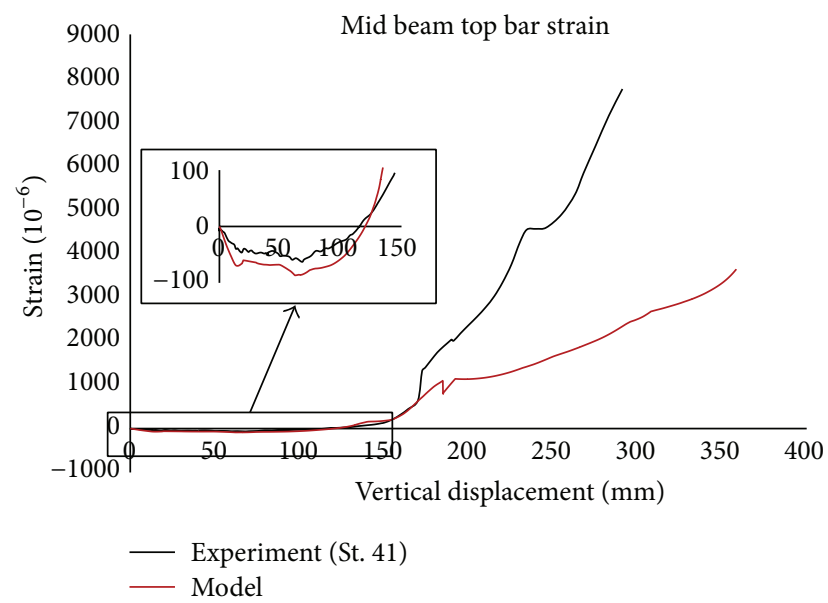

Figure 21: Strain in top reinforcing bar at mid span of beams.

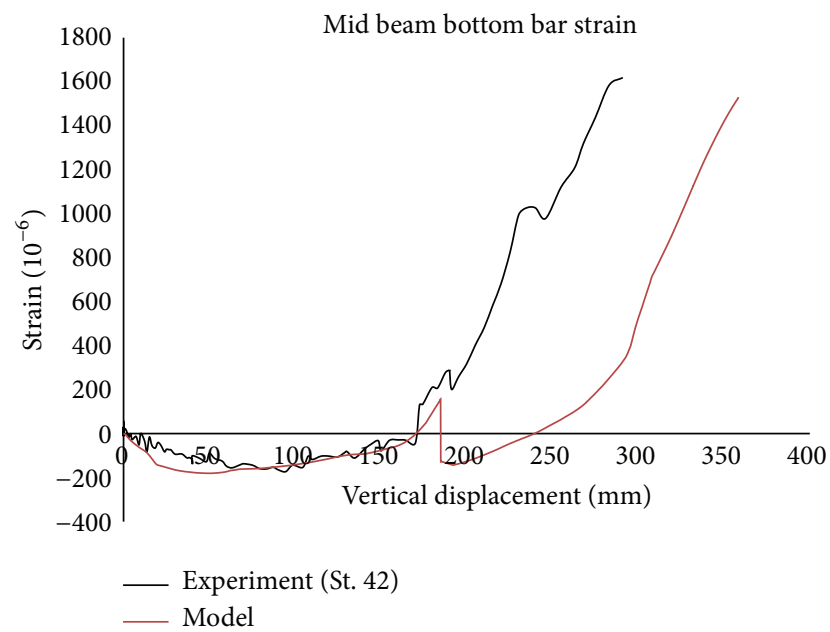

FIGURE 22: Strain in bottom reinforcing bar at mid span of beams. mechanism. The strength degraded in curve of deeper beam (M7) and suddenly dropped at the end of beam action. Consequently, CA in deeper beam started from low level of load capacity and had a smaller CA at final capacity. The effects of shear force with increasing in the beam height become more significant. In this analysis, because of relatively large value of length to depth ratio, the shear force on beam-column modeling was neglected.

In general, the results showed that the proposed numerical model with connection, which has five spring joint elements, predicted the behavior of RC subassemblages under the column removal scenario with good accuracy. This macromodel can be used to analyze frames with different geometric and boundary conditions and 3D frames because of the proposed characteristics of the joint element.

\section{Conclusion}

A scaled RC beam-column subassemblage was quasistatically tested under removal of the middle column scenario to investigate the structural behavior of the subassemblage and development of ALP mechanisms during progressive collapse. In addition, a macromodel with five spring joint elements was used to evaluate the different subassemblages under the column removal scenario. The results of this study are listed as follows:

(i) Similar to the full-scale specimen, scaled specimen accurately predicted structural behavior in progressive collapse. Despite similarity in general structural behavior, the number of cracks in full-scale specimen was more than scaled specimen. Moreover, cracks were distributed along the full-scale specimen which results in more ductile behavior in comparison with scaled specimen.

(ii) Comparison of load-displacement results of middle joint for scaled and full-scale specimens showed good agreements, and the capability of scaled specimen in order to estimate the behavior of subassemblage under progressive collapse scenario was evaluated.

(iii) The most significant characteristics of scaled specimen failure were spalling and crushing of the concrete at the top of the beam near the middle connection, development of flexural cracks at the beam-column joint interfaces, and fracture of the reinforcement rebar at the openings of the main flexural cracks.

(iv) The mechanisms for the ALPs of flexural action, CAA, and CA developed in the subassemblage. Compared to flexural action, CAA increased structural resistance by up to $30 \%$. Displacement of the compressive arch was about $40 \%$ of the beam height. In vertical displacement of about 1.3 times the beam height, CA developed and produced a maximum capacity in displacement of about twice the height of the beam. Because of the asymmetry in the profile of deformation in the subassemblage and the concentration of flexural cracking on one side of the middle joint, CA increased by just $20 \%$ of the structural capacity compared to flexural action. 


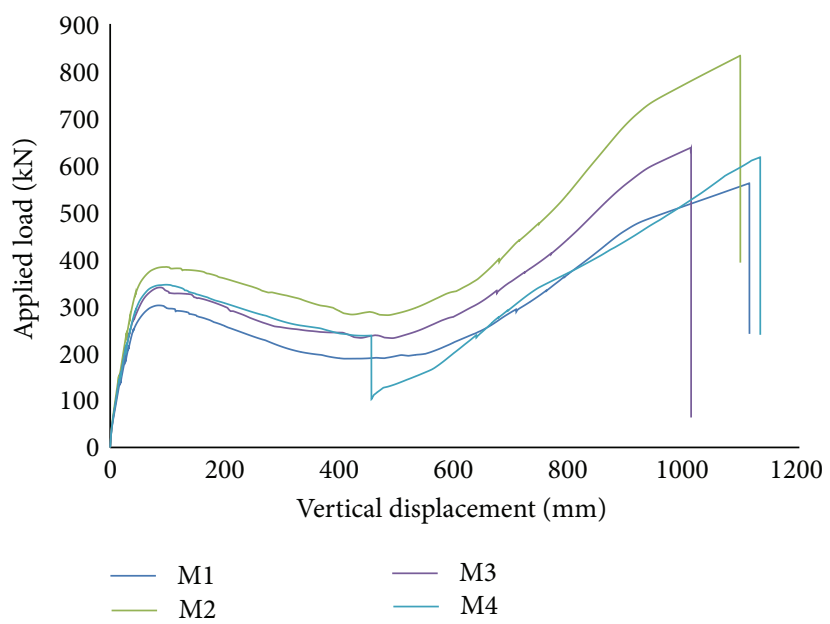

(a)

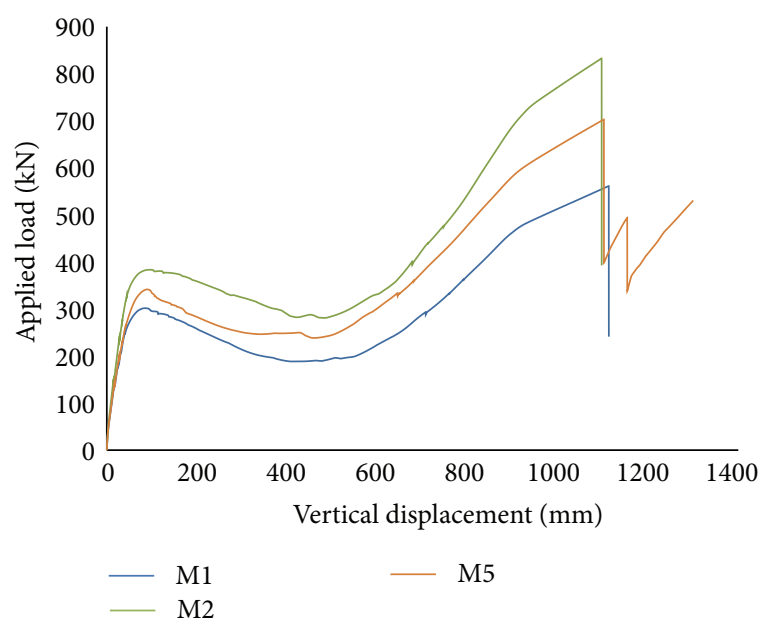

(b)

FIGURE 23: Effect of reinforcement on load-displacement curve.

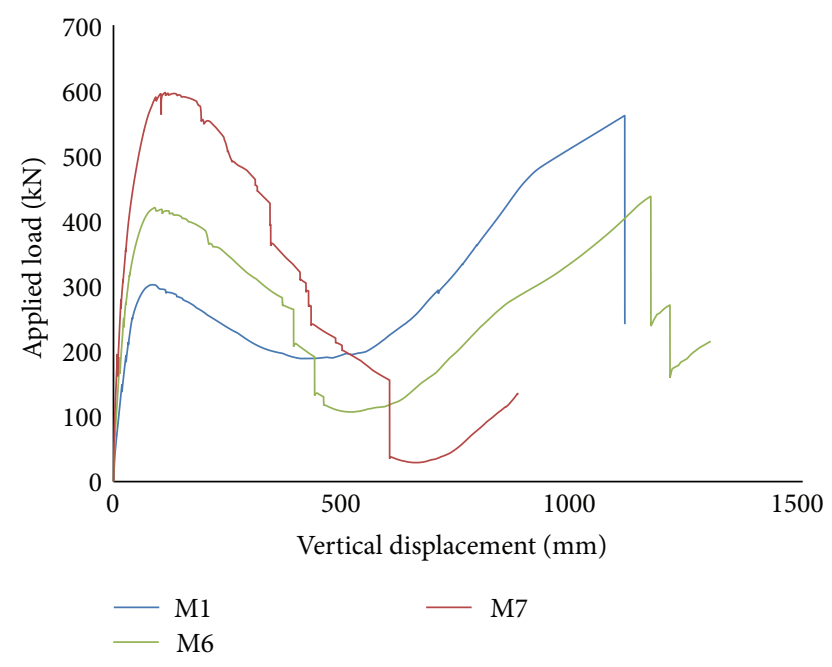

FIGURE 24: Effect of beam geometry on load-displacement curve with same reinforcement.

(v) The flexural behavior of the beam and column elements, shear behavior of the joint panel, and beamto-column connection interface behavior, including rebar bond-slip, were considered during the numerical modeling. The results showed that the numerical model can effectively simulate the structural behavior of the subassemblages under the column removal scenario. This numerical model can also be used to examine structures with different geometries and boundary conditions.

\section{Conflict of Interests}

The authors declare that there is no conflict of interests regarding the publication of this paper.

\section{References}

[1] American Society of Civil Engineers (ASCE), "Minimum design loads for buildings and other structures," SEI/ASCE 705, ASCE, Reston, Va, USA, 2005.

[2] Department of Defense (DoD), "Design of buildings to resist progressive collapse," UFC 4-023-03, Department of Defense (DoD), Washington, DC, USA, 2010.

[3] Y. H. Bao, S. K. Kunnath, S. El-Tawil, and H. S. Lew, "Macromodel-based simulation of progressive collapse: RC frame structures," Journal of Structural Engineering, vol. 134, no. 7, pp. 1079-1091, 2008.

[4] H. S. Lew, Y. Bao, S. Pujol, and M. A. Sozen, "Experimental study of reinforced concrete assemblies under column removal scenario," ACI Structural Journal, vol. 111, no. 4, pp. 881-892, 2014.

[5] H. S. Lew, Y. Bao, F. Sadek, J. A. Main, S. Pujol, and M. A. Sozen, "An experimental and computational study of reinforced concrete assemblies under a column removal scenario," NIST Technical Note 1720, 2011.

[6] W.-J. Yi, Q.-F. He, Y. Xiao, and S. K. Kunnath, "Experimental study on progressive collapse-resistant behavior of reinforced concrete frame structures," ACI Structural Journal, vol. 105, no. 4, pp. 433-439, 2008.

[7] J. Yu and K. H. Tan, "Experimental study on catenary action of RC beam-column sub-assemblages," in Proceedings of the $3 \mathrm{rd}$ International FIB Congress and Exhibition, Precast/Prestressed Concrete Institute, Chicago, Ill, USA, 2010.

[8] J. Yu and K. H. Tan, "Progressive collapse resistance of RC beam-column sub-assemblages," in Proceedings of the International Conference on Design and Analysis of Protective Structures, Defence Science \& Technology, pp. 74-83, Singapore, 2010.

[9] J. Yu and K.-H. Tan, "Experimental and numerical investigation on progressive collapse resistance of reinforced concrete beam column sub-assemblages," Engineering Structures, vol. 55, pp. 90-106, 2013.

[10] J. Yu and K. H. Tan, "Structural behavior of RC beam-column subassemblages under a middle column removal scenario," 
Journal of Structural Engineering, vol. 139, no. 2, pp. 233-250, 2013.

[11] Y. Su, Y. Tian, and X. Song, "Progressive collapse resistance of axially-restrained frame beams," ACI Structural Journal, vol. 106, no. 5, pp. 600-607, 2009.

[12] S. L. Orton and J. E. Kirby, "Dynamic response of a RC frame under column removal," Journal of Performance of Constructed Facilities, vol. 28, no. 4, 2014.

[13] Q. Kai and B. Li, "Dynamic performance of RC beam-column substructures under the scenario of the loss of a corner column-experimental results," Engineering Structures, vol. 42, pp. 154-167, 2012.

[14] J. Magnusson, M. Hallgren, and A. Ansell, "Shear in concrete structures subjected to dynamic loads," Structural Concrete, vol. 15, no. 1, pp. 55-65, 2014.

[15] T. Wang, Q. Chen, H. Zhao, and L. Zhang, "Experimental study on progressive collapse performance of frame with specially shaped columns subjected to middle column removal," Shock and Vibration, vol. 2016, Article ID 7956189, 13 pages, 2016.

[16] American Concrete Institute (ACI), Building Code Requirements for Structural Concrete and Commentary, ACI 318-02 and ACI 318R-02, American Concrete Institute, Farmington Hills, Mich, USA, 2002.

[17] H. G. Harris and G. M. Sabins, Structural Modeling and Experimental Techniques, CRC Press, Boca Raton, Fla, USA, 2nd edition, 1999.

[18] H. Jian and Y. Zheng, "Simplified models of progressive collapse response and progressive collapse-resisting capacity curve of RC beam-column substructures," Journal of Performance of Constructed Facilities, vol. 28, no. 4, Article ID 04014008, 2014.

[19] L. N. Lowes, N. Mitra, and A. Altoontash, "A beam-column joint model for simulating the earthquake response of reinforced concrete frames," Tech. Rep. PEER 2003/10, PEER, Berkeley, Calif, USA, 2003.

[20] N. Mitra and L. N. Lowes, "Evaluation, calibration, and verification of a reinforced concrete beam-column joint model," Journal of Structural Engineering, vol. 133, no. 1, pp. 105-120, 2007.

[21] F. McKenna, G. L. Fenves, and M. H. Scott, Open System for Earthquake Engineering Simulation-(OpenSees), University of California, Berkeley, Calif, USA, 2007, http://opensees.berkeley .edu.

[22] A. Altoontash, Simulation and damage models for performance assessment of reinforced concrete beam-column joints [Ph.D. thesis], Stanford University, Stanford, Calif, USA, 2004.

[23] F. J. Vecchio and M. P. Collins, "The modified compression-field theory for reinforced concrete elements subjected to shear," $A C I$ Journal, vol. 83, no. 2, pp. 219-231, 1986. 


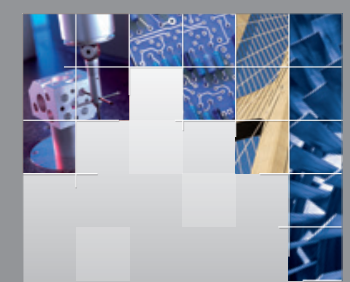

\section{Enfincering}
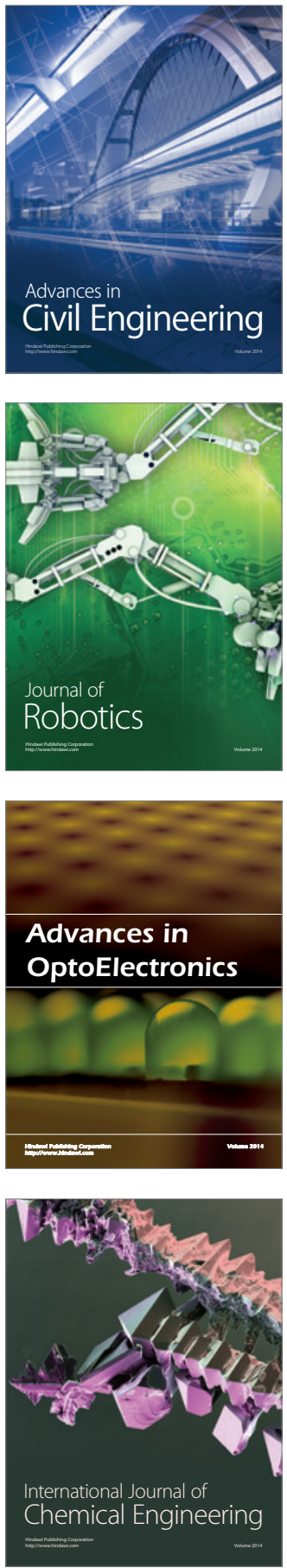

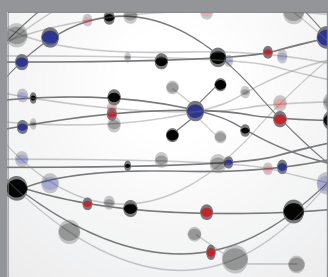

The Scientific World Journal

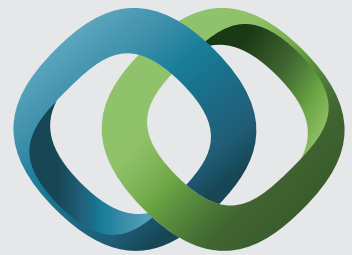

\section{Hindawi}

Submit your manuscripts at

http://www.hindawi.com
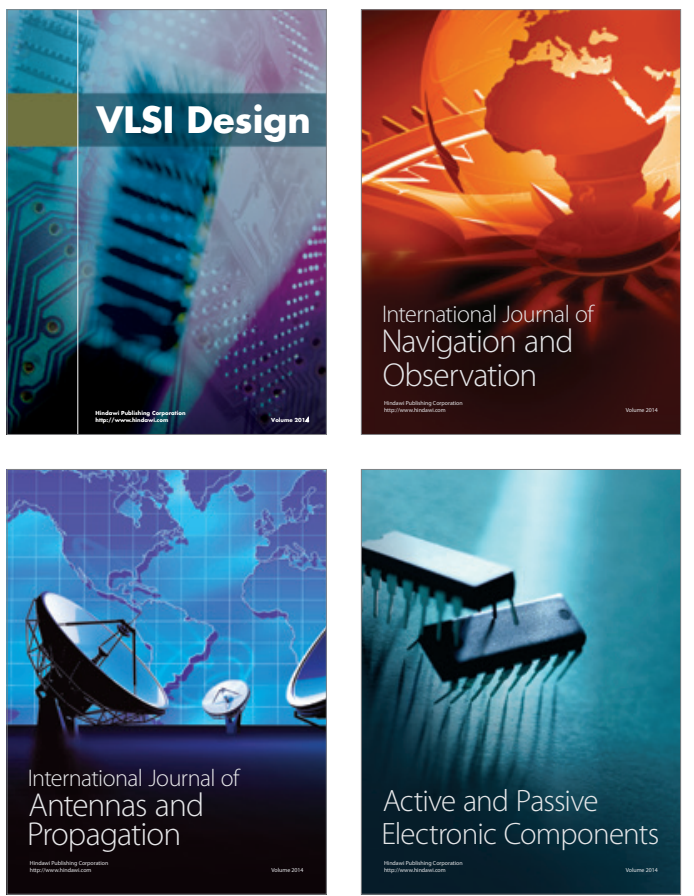
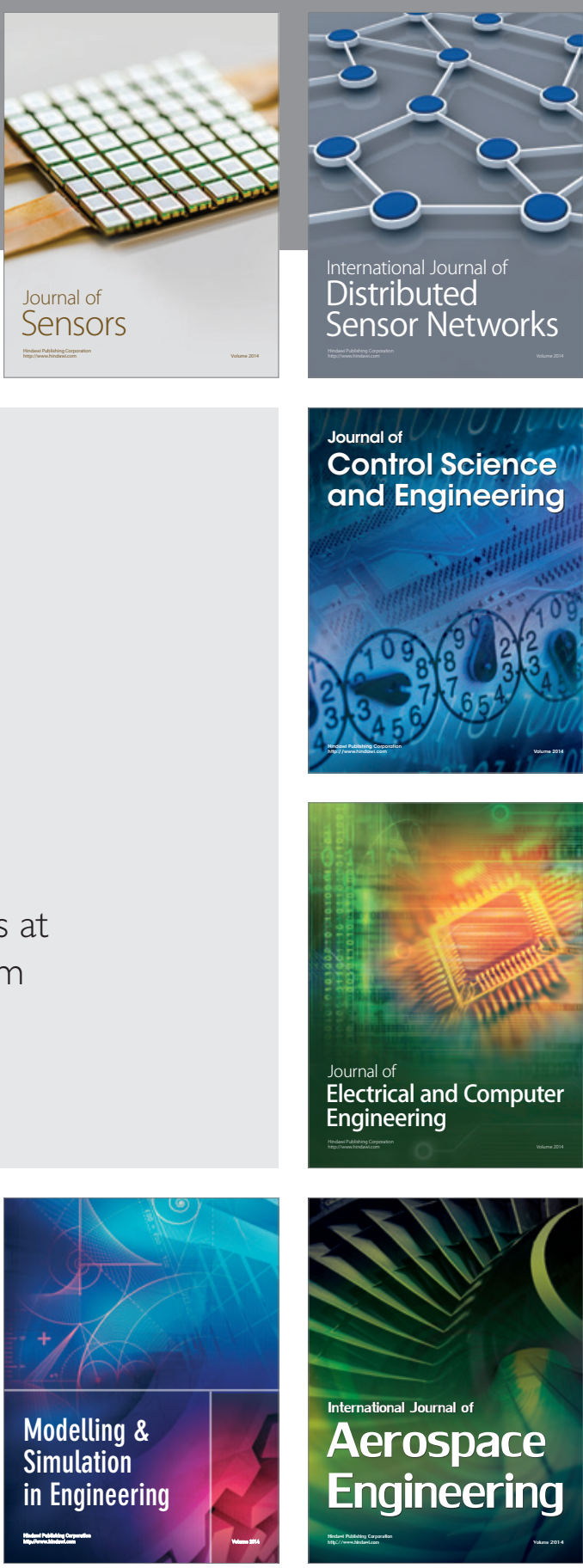

International Journal of

Distributed

Sensor Networks

Journal of

Control Science

and Engineering
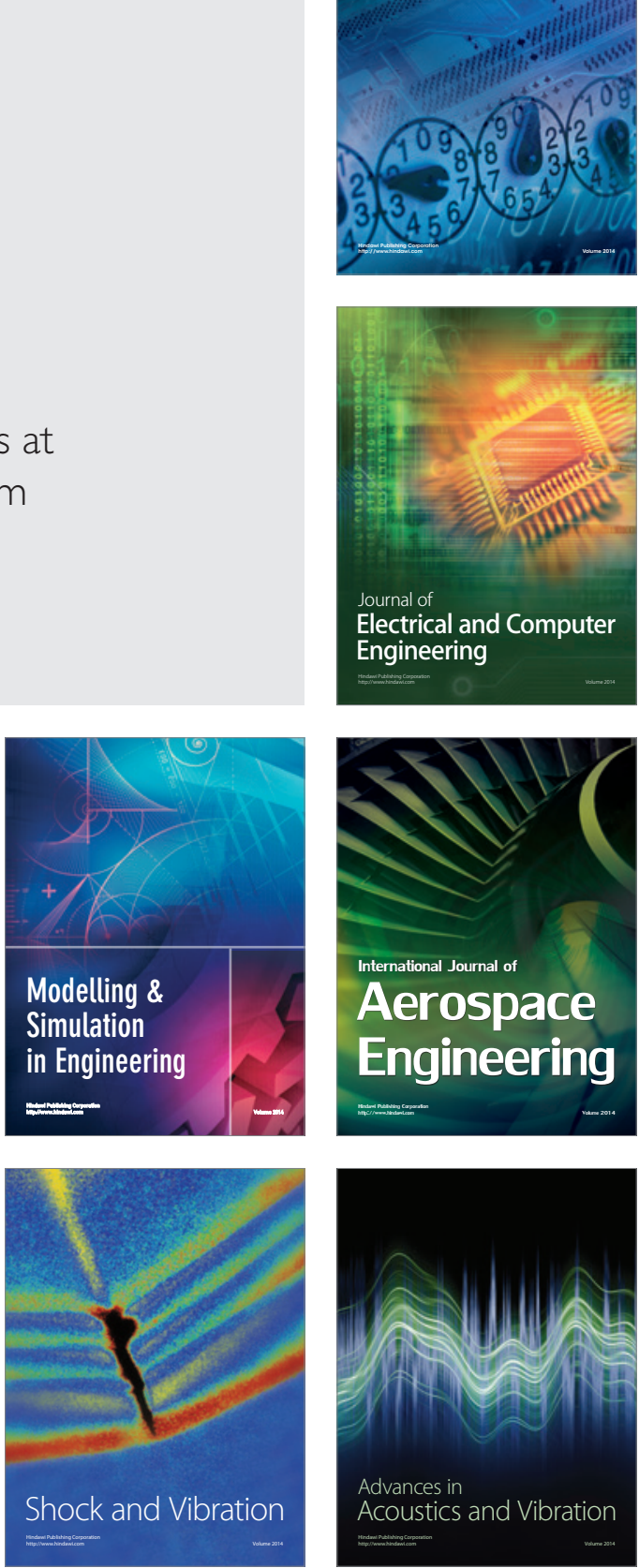